\title{
LA DELIMITACIÓN ENTRE LAS DIÓCESIS DE LUGO Y OVIEDO. ESCRITURA DIPLOMÁTICA Y TERRITORIALIDAD DIOCESANA A MEDIADOS DEL SIGLO XII*
}

\author{
POR \\ Miguel Calleja-Puerta ${ }^{1}$ \\ Universidad de Oviedo
}

\section{RESUMEN}

La delimitación territorial entre las diócesis fue uno de los procesos fundamentales de la Iglesia castellana en la Plena Edad Media. El dosier de documentos que respaldó la delimitación de las diócesis de Oviedo y Lugo a mediados del siglo XII hace ver que el asunto interesaba a los obispos, pero también a los reyes y los Papas. La reconstrucción de su génesis documental permite también comprobar las influencias diplomáticas entre distintas oficinas de producción documental.

PALABRAS CLAVE: Diplomática; diócesis; siglo XII; cancillerías.

\section{THE SETTLEMENT OF DIOCESAN BOUNDARIES BETWEEN LUGO AND OVIEDO. CHARTER WRITING AND DIOCESAN TERRITORIALITY AT MID-XIITH CENTURY}

\begin{abstract}
The settlement of boundary disputes was one of the main problems faced by the Castilian Church in the course of the twelfth century. The collection of charters reflecting the agreement between the dioceses of Oviedo and Lugo in 1150-1154 shows that the issue concerned not just bishops and parishes, but also kings and popes. The study of their process of drafting and diplomatic form allows to find a deep influence between papal, royal and episcopal offices in a time when new chancery practices were being introduced.
\end{abstract}

KEY WORDS: Diplomatics; Dioceses; XIIth century; Chanceries.

Cómo CITAR ESTE ARTículo / CITATION: Calleja-Puerta, M. 2019. "La delimitación entre las diócesis de Lugo y Oviedo. Escritura diplomática y territorialidad diocesana a mediados del siglo XIl». Hispania Sacra 71, 143: 39-57. https://doi.org/10.3989/hs.2019.003

Recibido/Received 11-12-2017

Aceptado/Accepted 22-02-2018

\section{INTRODUCCIÓN}

Ya hace más de un siglo que R. Poole justificaba la necesidad de estudiar la cancillería pontificia por el hecho de que su extensa influencia en la Cristiandad medieval se había ejercido principalmente a través de documentos escritos. ${ }^{2}$

\footnotetext{
* Trabajo realizado en el marco de los proyectos de investigación Escritura, notariado y espacio urbano en la Corona de Castilla y Portuga (siglos XII-XVII), ref. HAR2015-63676-P, y Poderes, espacios y escrituras en los reinos occidentales hispánicos (siglos XI-XIV), ref. HAR2013 42925P. Agradezco la amabilidad de cuantos archiveros me facilitaron el trabajo: D. Luis Miguel de la Cruz (Archivo Histórico Nacional), D. Gonzalo Fraga (Catedral de Lugo), D. Miguel Ángel González (Catedral de Orense) y D. Agustín Hevia (Catedral de Oviedo).

1 mcalleja@uniovi.es / ORCID iD: https://orcid.org/0000-00016683-2377

2 Poole 1915: 1.
}

Desde entonces, el inagotable caudal de la documentación romana ha seguido alimentando ediciones y estudios, y en las últimas décadas se ha abierto también a reconocer la huella de aquella cancillería pionera en otras oficinas de escritura de su tiempo. ${ }^{3}$ De este modo, la recepción de sus documentos participa en una de las líneas de investigación señeras en los actuales estudios diplomáticos, ${ }^{4}$ enriquece también el conocimiento de las cancillerías regias y episcopales, e ilumina las raíces culturales de sus productos.

El análisis de algunos casos permite ver, no obstante, que las influencias diplomáticas no iban en una única dirección. El propósito de este estudio es demostrar el complejo modo en que interaccionaban a mediados del siglo XII las

\footnotetext{
3 Singularmente a través de Herde y Jakobs 1999.

4 Vid. con carácter general Guyotjeannin y Morelle 2007.
} 
oficinas de reyes y obispos del occidente peninsular con los escritos que transmitían la autoridad papal. ${ }^{5}$ Cuando hay un testimonio cronístico de excepción, como la Historia Compostellana, se pueden ilustrar las complejas negociaciones que suele haber tras la concesión de documentos que parecen poco expresivos. ${ }^{6}$ Pero cuando estos se organizan de forma seriada, como ocurre en el caso que estudiamos, el testimonio diplomático resulta igualmente significativo.

En efecto, la solución de los conflictos entre las diócesis de Oviedo, Lugo y Orense a mediados del siglo XII ofrece un panorama ejemplar del complejo circuito documental que estaba articulando la Iglesia hispana con sus instituciones de referencia: por una parte el Papado romano, por otra la monarquía. Su excepcionalidad radica en que ilumina un panorama de negociaciones en el que se aúnan cesiones regias, acuerdos entre diócesis y refrendo pontificio de las decisiones adoptadas en el reino de León y Castilla. Una parte de los documentos que sirven de base a nuestro estudio habían sido ya editados y eran conocidos por diversos estudiosos a escala local. Pero es su análisis conjunto y la adición de testimonios inéditos lo que dota de valor al grupo, permite su estudio comparado y ofrece la posibilidad de ver la transferencia de influjos culturales entre distintas oficinas en una época en que la actividad diplomática se multiplicaba. ${ }^{7}$

\section{REORGANIZACIÓN Y CONFLICTO ENTRE LAS DIÓCESIS DEL NOROESTE}

En el complejo proceso de reorganización de las diócesis peninsulares a lo largo del siglo XII, la delimitación de sus territorios se convirtió en uno de los problemas más graves. ${ }^{8}$ Detrás de algunos de estos enfrentamientos están silvas textuales célebres y aún poco explicadas, como la División de Wamba o el Parroquial suevo. ${ }^{9}$

La diócesis de Oviedo, nacida al calor de la monarquía astur, no fue ajena al proceso. ${ }^{10}$ Hacia 1120 , el cartulario compuesto en su catedral atribuía al rey Alfonso II (791-842) la fundación de la sede y la concesión de un extenso territorio. ${ }^{11}$ Sin embargo, las diócesis rivales manejaron aquella memoria añadiéndole matices nuevos. El relato que se ha conservado en Lugo y en Braga ponía el origen del problema

5 El capítulo que dedicó R. A. Fletcher (1978: 121) al documento episcopal leonés del siglo XII acentuaba el delicado balance entre receptividad al influjo romano e influencia del modelo regio. Se refiere precisamente a documentos lucenses de los años treinta. En el mismo sentido, Ostos Salcedo 1995: 433. De todos modos, algunos acuerdos interdiocesanos reflejaban un mayor peso de la diplomática pontificia, según Fletcher 1994: 481.

6 Reglero de la Fuente 2014: 45-48.

7 El corpus documental básico que sustenta este estudio se edita, corrigiendo publicaciones previas, en el apéndice final de este trabajo.

8 Fletcher 1978: 141-144; 1994: 480-482; Reglero de la Fuente 2006; Domínguez Sánchez 2013; Cunha 2017.

9 Henriet 2008: 291.

10 Sus conflictos con Lugo ya fueron sintetizados por Cañizares 1944. A eso se sumaban sus dificultades con Toledo una vez que Urbano Il la sometió a la archidiócesis toledana (Dominguez Sánchez 2003: 62-63). Los esfuerzos del obispo Pelayo por hacer descender su diócesis de una supuesta fundación vándala en Lucus asturum parecen motivados por su deseo de no haber dependido nunca su territorio de otra sede. Vid. con carácter general Mansilla Reoyo 1994, vol. II: 26-36.

11 Sanz Fuentes 1995a. No es propósito de este trabajo el seguimiento pormenorizado de los territorios disputados, sino las estrategias documentales empleadas para su control. en la conquista musulmana de la Península Ibérica: Braga y Orense estaban despobladas, sus dignidades se habían trasladado a Lugo, y solo en esas circunstancias se habían cedido a la nueva diócesis de Oviedo los territorios que les daba el Rey Casto.

En efecto, en Lugo se conservaron al menos dos refacciones en visigótica redonda por las que el Rey Casto disponía así las cosas, ${ }^{12}$ y aquel documento conoció fortuna, ya que se han conservado sendas copias algo más tardías del mismo, tanto en el Tumbo Viejo de Lugo, ${ }^{13}$ como en el Liber Fidei de Braga. ${ }^{14}$ En ambos la copia parece tener una intención bastante clara, que se enfatiza en la segunda versión que transmite el cartulario bracarense. Allí se especifica que "si auxiliante Deo post nostrum excessum ciuitates supradicte que destructe nunc esse uidentur a Christianis fuerint recuperate, ad proprium reddiderint decus ut Lucensi ecclesie sue prouincie et ecclesie supra nominate restituantur, et unaqueque ciuitas sua recipiat confinia». En efecto, ahora que las sedes de Braga y Orense estaban de nuevo restauradas, llegaba el momento de las reintegraciones. Por eso surgen también pronto las sospechas de manipulación, al reconocer en el texto territorios que con el paso del tiempo se identificarían como arcedianatos -Abeancos, Deza, Sarria, Neira, Saviñao, Páramo, Monforte, Camba-, y que parecen reflejar bien las preocupaciones del siglo XII.

El conflicto de Oviedo con Orense se conoce peor, y no será ahora objeto de estudio. En Lugo, sin embargo, las reivindicaciones parecen haber comenzado pronto, si es que se puede confiar en la ingenuidad de varios documentos de su Tumbo Viejo. A fines del siglo XI el obispo Amor (1088-1096), que había fortalecido su señorío en la ciudad y procedido a la reforma del cabildo, ${ }^{15}$ emprende también el intento de recuperar los territorios perdidos, remontando su legítima posesión a los tiempos míticos del obispo Odoario. ${ }^{16}$ Amor debió llevar lejos sus reclamaciones. Es posible que haya acompañado en 1095 al concilio de Clermont al obispo compostelano Dalmacio, que participó en el mismo «cum quibusdam

12 Una está hoy en el AHN, Códices, L417, pergamino cosido al final con el no 84, cuya confección fijó en los siglos XI-XII Floriano Cumbreño 1946, vol. I: 192. La otra fue descrita en el Archivo de la Catedral de Lugo por Mosquera Agrelo 2002b: 217. Quedan en el archivo catedralicio lucense varias confirmaciones posteriores, también falsas; se ha referido a ellas Barrau-Dihigo 1919: 120-122.

${ }_{13}$ El Tumbo Viejo de Lugo, compuesto a principios del siglo XIII, recoge la donación de Alfonso II y la referencia a los territorios cedidos a Oviedo: «necessitate compulsus, terras et prouintias Sancto Saluatoris Ouetensi concedo Ecclesie que ante fuerant subdite Lucensi Ecclesie per cuncta seculorum tempora. Hec sunt autem nominata prouintie, id est Valbonica, Neria, Flammoso, Sarria, Paramo, Frolani, Sauinianos et Sardinaria, Auiancos, Asma, Camba et ecclesias de Dezon» (López Sangil y Vidán Torreira 2011: 48-52). Sobre la fiabilidad del códice, Fernández de Viana y Vieites 2003-2004: 595.

14 Pero así se recoge también en Braga, donde el Liber Fidei copia exactamente la misma relación de lugares: «necessitate compulsus, terras et provintias Sancti Salvatori Ovetensi concedo ecclesie que ante fuerant subdite Lucensi ecclesie per cuncta seculorum tempora. Hee sunt autem nomina provintie, id est Vallonca, Neira, Flamoso, Sarria, Paramo, Froilani, Savinianos et Sardinaria, Aviancos, Asma, Camba et ecclesias de Decon» (Marques 2016: 62).

15 D'Emilio 2008: 200-202.

16 Así lo defiende una relación de los hechos que llega a los tiempos del obispo Pedro, sucesor de Amor, y que en el Tumbo Viejo se pone bajo el epígrafe de carta de tributis inter Lucensem et Ouetensem ecclesias (López Sangil y Vidán Torreira 2011: 165-166). 
comprovincialium episcoporum $" ;{ }^{17}$ así lo sugerirían al menos las letras de Urbano II (1088-1099) a los obispos de León, Mondoñedo y Oviedo ordenando la restitución de ciertas parroquias. ${ }^{18}$ En un reino donde apenas se reciben documentos pontificios antes del 1100, esta disposición en beneficio de la Iglesia de Lugo sobresale de manera muy particular.

Sin embargo, y en circunstancias cuyo detalle se nos escapa, las pretensiones reflejadas en el Tumbo Viejo tardaron largo tiempo en ser respondidas, y las siguientes décadas destacan por las reiteradas y no cumplidas disposiciones papales al efecto. Explicar el proceso en su complejidad no será posible hasta que concluyan los trabajos de la Iberia pontificia. De todos modos, pueden reunirse noticias útiles. En 1110 Pascual II (1099-1118) habría instado a las Iglesias de Oviedo y Lugo a arreglar sus diferencias o, en su caso, a poner su resolución en manos de los obispos de Compostela y Orense. ${ }^{19}$ Representantes de la Iglesia lucense estaban en la curia pontificia poco antes del primer concilio de Letrán de $1123,{ }^{20}$ cuando Calixto II (1119-1124) habría confirmado sus posesiones en términos similares a las cesiones que se atribuían a Alfonso II: «infra antiquos parrochiae tuas terminos... uidelicet Nauiam, Uallem Carceris, Flamosam, Neiram, Sarriam, Froilanos, Lemos, Asma, Auiancos, Camba, Dezom $" .{ }^{21}$ Debe observarse, de todos modos, que la suscripción de Hugo como canciller pontificio en este documento entra en conflicto con el que lo era por entonces, Aimerico. Del mismo modo, tampoco tenemos claro cuánto hay de cierto en la idea de que en 1129 y 1130 los cardenales legados Guido y Humberto se ocuparan de la sede, ${ }^{22}$ o en la noticia de que el concilio de Carrión de 1130 dictaminase la restitución de las parroquias de Aviancos, Camba, Asma, Lemos, Froilanos, Sarriam, Paramum, Flamosum, Neiram, Naviam, Vallonga, Buraon. ${ }^{23}$

Otros testimonios, ajenos al Tumbo Viejo, acreditan que el conflicto estaba abierto desde el primer tercio del siglo; en fecha incierta de su tercera década el obispo Pedro III de Lugo (1113-1133) dejaba a la mesa capitular algunas iglesias en las comarcas de Fornadeiros y Chamoso, quejándose de que "Ouetum in predictis partibus episcopalia iura, licet iniuste, tenebat». ${ }^{24}$ Del mismo modo, los documentos pontificios que ilustran el caso en esta década parecen más fiables en lo que hace a su génesis; eso parece al menos ante el privilegio de 1131 por el que Inocencio II (11301143) confirmó las parroquias que ocupaban ilegítimamente los obispos vecinos: "Nauiam uidelicet, Uallecarceris, Flamosam, Neiram, Sarriam, Froilanos, Parmam, Lemos, Asmam, Auiancos, Cusancam». ${ }^{25}$ En fin, la versión de la crónica de Sampiro elaborada en el entorno del obispo Pelayo de Oviedo (1100-1130) por estos mismos años insistía en la temprana protección pontificia de la diócesis, suponía la celebración de un concilio en Oviedo en tiempos de Alfonso

17 Falque Rey 1988: 18; Fletcher 1978: 184.

18 López Sangil y Vidán Torreira 2011: 176-177.

19 Ibídem: 178. Cinco años antes, el obispo Pedro de Lugo ya había actuado como informante del pontífice en el conflicto entre Compostela y Mondoñedo por el arciprestazgo de Trasancos.

20 Fletcher 1978: 204.

21 López Sangil y Vidán Torreira 2011: 178-182.

22 Mosquera Agrelo 2002a: 45.

23 Cañizares del Rey 2014: 263.

24 López Sangil y Vidán Torreira 2011: 214-218.

25 Ibídem: 180-181.
III (866-910), y declaraba la concesión de los términos de su diócesis, todos concordes, con un detalle muy superior a los ejemplos anteriores. ${ }^{26}$

Pero pasaban los años. El obispo Pedro III destacaba entre los prelados del reino por unas relaciones con Roma que se manifestaban fluidas y consolidaba la reforma interna, pero el problema con Oviedo seguía sin resolver. Los acontecimientos se precipitaron a mediados de siglo, en un momento en que se acababan de restaurar las diócesis de Lisboa, Lamego y Viseu, y se recrudecían los conflictos entre Compostela y Braga. ${ }^{27}$

\section{LA INTERVENCIÓN REGIA EN EL CONFLICTO DIOCESANO}

Algunas noticias poco claras, transmitidas por Pallares a principios del siglo XVIII, aseveran que en 1146 Alfonso VII (1126-1157) «concordó a Gidón, obispo de Lugo, con el de Oviedo, con auctoridad apostólica y consentimiento de los prelados de España. $Y$ en tiempos del obispo Juan tercero huvo otra concordia». ${ }^{28}$ De la primera no tenemos ninguna otra noticia, pero la segunda aún puede estudiarse de forma detenida.

Quizá Roma estaba demasiado lejos para influir de forma efectiva en la vida eclesiástica de un reino que llevaba siglos actuando al margen de la autoridad pontificia, pero poco a poco su influencia se iba haciendo mayor. Así que en [1148] el papa Eugenio III (1145-1153) volvió a insistir en la cuestión, ya con peor tono. Tras un preámbulo en que declaraba la prohibición de que "alterius parrochie terminos nullus usurpet», ${ }^{29}$ recordaba que las disposiciones de los legados Humberto y Guido ya habían dispuesto la restitución de dichas parroquias a Lugo, y que ahora él mismo había ordenado la ejecución de la sentencia en el concilio de Reims: «in Remensi concilio uiua uoce tibi mandabimus». En suma, y por escrito, el pontífice instaba al obispo de Oviedo a restituir a la sede lucense las parroquias en litigio en plazo de 40 días.

Paralelamente, Eugenio III escribió directamente a las parroquias en disputa, "dilectis filiis clero et populo de Lemos, de Sarria, de Flamoso, de Paramo, de utraque Neira, de Navia de Suarna, de Buraon, de Vallonga, de Ambiacos, de Lamba et de Asma», ordenándoles que obedecieran al

\footnotetext{
26 «In Gallecia Suarnam cum possessionibus Sancti Martiniet Sancte Marie de Uilla Auoli cum ómnibus suis apendiciis; Vallem Longam et possessionem sancte Marie cum omnibus suis apendiciis. Neram cum possessionibus suis Sancti Martini de Asperella et Sancti lacobi de Couas cum ómnibus apendiciis earum. Lamosam, et possessionem Sancti Martini de Perrelinos cum ómnibus suis apendiciis. Totam Sarriam, et possessionem sancte Marie de Corueli cum ómnibus suis apendiciis. Paramum usque ad flumen Mineum. Totam Lemos cum Vnicio, et Verosino, et Sauiniano, et Froiane usque ad flumen Silum. Totam Limiam cum ecclesiis de Petrario que edificate sunt uel fuerint inter Arnoium flumen et Silum a termino montis Baron, et per aquam Zore usque in fundum Arnoie, et per ipsum discursum usque flumen Minium. In Ueza usque in Portellam de Uanati. Et ecclesias de Sallar inter Arnoiam et Silum cum ecclesiis de Barrosa, Castellam, et possessionem Sancti Saluatoris de illas mesas, Cusancam, Barbantes, Auia et Auion, Asma, Camba, Auiancos. Et posesiones ecclesie sancte Crucis de Soto Senatori cum ómnibus suis apendiciis» (Pérez de Urbel 1952: 302-304).

27 Marques 1996.

28 Pallares y Gayoso 1700: 255. Se remite al legajo de reales privilegios, número 3 del archivo.

29 Marques 2016: 336.
} 
obispo Guido de Lugo (1136-1152) como su ordinario. ${ }^{30}$ Les exponía que al obispo de Oviedo, que las tenía illicite occupate, ya le había ordenado su reintegración «tam litteris quam viva voce»; y que finalmente el prelado ovetense había acatado sus órdenes, "mandatis nostris iam, sicut debuit, humiliter obedivit».

Pero para facilitar las cosas, Eugenio III debió de activar también la vía de la influencia regia, aprovechando una época de estrechos contactos con Alfonso VII. ${ }^{31}$ Que las relaciones eran fluidas lo evidencia de nuevo un documento original de febrero de 1148 fechado en Palencia, «quando prefatus imperator habuit ibi colloquium cum episcopus et baronibus sui regni, de uocatione domini Pape ad concilium ${ }^{32}$ y la carta en la que Eugenio III, entre otras cosas, le agradecía a Alfonso VII el interés que había puesto en que los obispos de su reino acudiesen al concilio de Reims. ${ }^{33}$

La prueba de que el pontífice acudió a la autoridad regia para solucionar este conflicto se encuentra apenas dos años después. En febrero de 1150, en Peral de Arlanza, Alfonso VII privilegiaba a la diócesis de Lugo mediante un documento original motivado con claridad (doc. 1): el Papa le había impuesto como penitencia solucionar la antigua discordia entre las sedes; de modo que, con el consejo del arzobispo de Toledo y de otros obispos, había establecido un pacto por el que compensaría a la Iglesia de Oviedo por lo que ahora perdía. Y en efecto, a los pocos días entregaba a esta las iglesias de Santa Marina y Santa Gadea de dicha ciudad, según las había poseído su abuelo Alfonso VI (10651109) (doc. 2). Al haberse perdido su texto no es posible saber si el monarca motivaba su donación, pero parece claro que se trataba de la anunciada compensación, ${ }^{34}$ sobre todo cuando vemos que el mismo día dirige a la catedral de Orense otro privilegio, que sí se ha conservado en su estado original, relativo de nuevo a devolución de parroquias en disputa con Oviedo (doc. 3); a mayor abundamiento, coincide además en el tiempo con el scriptum libertatis por el que el obispo de Oviedo declara la no sujeción a su diócesis del monasterio de San Julián de Samos, aconsejado por el Emperador y el primado toledano (doc. 4).

En definitiva, los problemas entre las tres diócesis se entrecruzaban, y los documentos regios también. Los de Lugo y Orense se han conservado en su estado original, están escritos por la misma mano y su tenor documental guarda estrechos paralelismos. No son iguales los preámbulos, aunque en esencia ambos recogen de forma estereotipada la habitual obligación regia de proteger a las instituciones eclesiásticas. ${ }^{35}$ En el mismo sentido, numerosas diferencias los separan: la intitulación individual en un caso y conjunta en otro, o la larguísima motivación de la cesión a Orense, que explicita con más claridad lo que unos días antes apenas

30 Ibídem: 337.

31 Reilly (1978: 38) ha subrayado las limitaciones de la Iglesia postgregoriana para imponer sus planteamientos en Castilla.

32 Archivo de la colegiata de San Isidoro de León, pergamino 146.

33 «Episcopos et abbates regni tui ad vocationem nostram, tanquam devotus et humilis filius, Remense interesse concilio voluisti» (Migne 1855, tomus CLXXX, cols. 1345-1347).

34 Del mismo modo no parece casual su coincidencia en el tiempo con la delimitación del arcedianato de Oviedo, fechada un mes más tarde y hecha «pro salute gloriosissimi imperatoris domni [Adefonsi], sub cuius imperio est facta concessio» (García Larragueta 1962: 403-406).

${ }_{35}$ Calleja-Puerta 2018: 196. se anunciaba. También es muy singular que el documento lucense pudo haber sido sellado, según revelan tres orificios en disposición triangular en el borde inferior del pergamino, que faltan sin embargo en el diploma de Orense. ${ }^{36}$

Pero como contrapartida destaca un paralelismo llamativo en algunos pasajes, según se aprecia en el cuadro 1, y muy particularmente en la motivación. Todo esto permite pensar que uno sirvió al otro de modelo en lo esencial y que luego se adaptó a cada caso particular. Hay que llamar la atención sobre el paralelismo existente entre la cláusula de motivación de ambos textos, separados por unos días de diferencia, en la que se reproducen singularmente hasta los lapsus: en ambos casos, la palabra iustitia se escribió erróneamente como iustia.

\section{CUADRO № 1}

\begin{tabular}{|c|c|}
\hline Orense & Lugo \\
\hline $\begin{array}{l}\text { videns aeclesiam Auriensem } \\
\text { in magna fatigatione positam } \\
\text { pro discordia que diu inter } \\
\text { aeclesiam Ouetensem et } \\
\text { ipsam aeclesiam Auriensem } \\
\text { exagitabatur, quia mihi a } \\
\text { Deo et ad sede apostolica in } \\
\text { penitentia commissum est } \\
\text { ut aecclesias Dei in ius<ti>tia } \\
\text { regam }\end{array}$ & $\begin{array}{l}\text { uidens aecclesiam Lucensem } \\
\text { in magna fatigatione positam } \\
\text { pro discordia que diu inter } \\
\text { aecclesiam Ouetensem et } \\
\text { ipsam Lucensem aecclesiam } \\
\text { exagitabatur, quia mihi a } \\
\text { Deo et a sede apostolica in } \\
\text { penitencia et in remissione } \\
\text { peccatorum meorum } \\
\text { commissum est ut aecclesias } \\
\text { Dei in ius<ti>tia regam. }\end{array}$ \\
\hline $\begin{array}{l}\text { fatio kartam donationis et } \\
\text { textum firmitatis Deo et } \\
\text { aecclesie Sancti Martini } \\
\text { de Aurenis et uobis } \\
\text { domno Martino, Auriensi } \\
\text { aepiscopo et omnibus uestris } \\
\text { successoribus, de diocesi illa } \\
\text { superius nominata }\end{array}$ & $\begin{array}{l}\text { fatio kartam donationis et } \\
\text { textum firmitatis Deo et } \\
\text { aecclesiae Sancte Marie } \\
\text { Lucensi et uobis aepiscopo } \\
\text { domno Guidoni et omnibus } \\
\text { successoribus uestris de omni } \\
\text { diocesi illa de qua discordia } \\
\text { inter Ouetensem ecclesiam et } \\
\text { aecclesiam uestram erat }\end{array}$ \\
\hline $\begin{array}{l}\text { Et quando ego uel aliquis } \\
\text { ex generatione mea hanc } \\
\text { concambiationem inter } \\
\text { aeclesiam Ouetensem et } \\
\text { Auriensem aeclesiam fecero, } \\
\text { quod uos domnus Martinus, } \\
\text { Auriensis aepiscopus, uel qui } \\
\text { in loco vestro [in Auriense] } \\
\text { ecclesia aepiscopus fuerit, } \\
\text { tribuat mihi uel qui in regno } \\
\text { meo rex fuerit illas LXXXa } \\
\text { marchas que modo remanent, } \\
\text { et hoc factum semper sit } \\
\text { firmum. }\end{array}$ & $\begin{array}{l}\text { Et quando ego fecero } \\
\text { concambiationem inter } \\
\text { Ouetensem aecclesiam et } \\
\text { ipsam aecclesiam uestram, } \\
\text { sicuti iam facere uolui, quod } \\
\text { dem de propriis regalibus } \\
\text { meis aecclesiae Ovetensy, ut } \\
\text { uos uel successor uester qui } \\
\text { in Lucensi aecclesia in loco } \\
\text { uestro aepiscopus fuerit, } \\
\text { tribuat mihi uel successori } \\
\text { meo qui in loco meo rex } \\
\text { fuerit, illos alios morabitinos } \\
\text { quos modo remanent, sicuti } \\
\text { inter me et uos firmatum } \\
\text { est, et hoc factum semper sit } \\
\text { firmum. }\end{array}$ \\
\hline
\end{tabular}

Y desde luego, el procedimiento seguía su curso. Más allá de desbloquear la situación, garantizando las rentas diocesanas lucenses, ${ }^{37}$ el monarca se presentaba como el

36 Sobre los sellos de Alfonso VII, Menéndez Pidal de Navascués 1998. No debe excluirse, sin embargo, que el sellado se haya producido con posterioridad.

37 Se compromete a que él ni sus sucesores desposeerán en lo sucesivo a la Iglesia de Lugo, algo que recuerda la práctica regia de beneficiarse a la muerte de los obispos de las rentas de algunas sedes, según 
muñidor de los acuerdos futuros entre Lugo y Orense con Oviedo. Por un lado, se comprometía a compensar a la Iglesia ovetense con ciertas regalías; por otro, corroboraba su compromiso previo con la sede lucense respecto a «illos alios morabitinos quos modo remanent, sicuti inter me et uos firmatum est»; del mismo modo garantizaba a Orense la recuperación de sus territorios, recibía a cambio setenta marcas de plata, y quedaba pendiente la recepción de otras ochenta para el momento en que los problemas con Oviedo quedasen definitivamente zanjados.

El desenlace del conflicto con Orense no está documentado $^{38}$, pero el de Lugo sí. Quizá la muerte de Guido, obispo de Lugo, ocasionó un nuevo retraso en la resolución del problema, pero esta se hizo efectiva en la prelacía de su sucesor, el obispo Juan (1152-1181). Se sabe de este que había sido abad de Samos, y se presuponen unas buenas relaciones con el monarca habida cuenta de que el propio Alfonso VII confirmó primero el coto de la abadía en $1146,{ }^{39}$ y recomendó luego a Juan ante la sede bracarense en el momento de pedir su consagración. ${ }^{40}$ De este modo, ha sido calificado como hombre del rey y quizá representante suyo en un par de embajadas a Roma, ${ }^{41}$ en cuyo transcurso participó personalmente en el concilio de Beauvais de 1160, acentuando así su proximidad a Alejandro III (1159-1181). ${ }^{42}$ De la misma manera, el obispo Juan aparece también como fiel servidor de Roma, que medió con el rey en la disputa por el nombramiento del arzobispo Martín de Compostela (1156-1167), obtuvo documentos de Alejandro III y quizá acudió al III Concilio de Letrán en 1179, amén de reformar el cabildo a instancias del legado Jacinto (1144-1191)..$^{43}$

Las buenas relaciones con el monarca, en efecto, se manifiestan desde el principio de su prelacía. En octubre de 1153 ya consigue para sus canónigos la inmunidad de sus bienes y personas con una caloña de 500 sueldos, ${ }^{44}$ precisamente en un documento que es de los primeros en utilizar un preámbulo de resonancias imperiales. Y esa buena relación facilitaba que se pusiesen los medios para la solución del problema con Oviedo.

Es relevante el hecho de que el arreglo fue anterior a la llegada del cardenal Jacinto al reino, que lo visitó como legado pontificio entre julio de 1154 y marzo de $1155 .{ }^{45}$ De hecho, sabemos que Jacinto participó en otros conflictos de límites, atendiendo en los concilios de Valladolid y Palencia la reclamación de Lugo a la diócesis de León por Triacastela. ${ }^{46}$ El problema era el mismo, que la cesión había sido condicional hasta la restauración de Braga y Orense.

describió para Compostela R. A. Fletcher 1977: 342. Ha subrayado e recurso habitual de los reyes a los tesoros de las catedrales Reglero de la Fuente 2014: 49.

38 Sería de esperar la anunciada donación del castillo de Goela y la jurisdicción de Laviana, que sin embargo no ha dejado noticia en el archivo catedralicio ovetense.

39 Lucas Álvarez 1986: 168-170.

40 Caso excepcional de aprobación del monarca. Lo edita Marques 2016: 496-497, 531 y 791.

41 Fletcher 1978: 66.

42 Fletcher 1977: 350

43 Fletcher 1978: 67.

44 Archivo de la Catedral de Lugo, Regios, no 4.

45 Recoge los documentos relativos a dicha legación Weiss 1995: 175-179.

${ }^{46}$ Se conserva un diploma legatino al respecto en Archivo de la Catedral de Lugo, Pontificios, leg. 3, no 5.
Pero en nuestro caso la mediación regia parece ser la realmente efectiva. Se produce en Salamanca en los primeros días de enero de $1154,{ }^{47}$ y se expresa mediante sendos privilegios que de nuevo se adaptan a cada uno de los destinatarios. El contexto no puede ser más solemne, hasta el punto de que recoge a diecinueve obispos como testigos. En vista de esa afluencia se ha calificado a esta asamblea como reunión conciliar, ${ }^{48}$ pero es interesante subrayar que no hay tal, o que es un concilio al antiguo modo hispánico, como podía haberlo sido el de Coyanza, un siglo atrás, con presencia del rey y sin contacto con Roma.

El día 2 de enero, Alfonso VII dona a la Iglesia de Oviedo y a su obispo Martín (1143-1156) el castillo de Suarón y la tierra de Las Regueras, llamados a convertirse en ambos casos en dos de las más importantes jurisdicciones del señorío episcopal ovetense (doc. 5). Dicho diploma no se ha conservado en su forma primigenia, pero aún así resulta llamativa la similitud entre su tenor y el original que un día más tarde refleja una concesión paralela a la Iglesia de Lugo (doc. 6). Ello se evidencia sobre todo en el protocolo, en su expresión más formularia. Se reitera el preámbulo que había estrenado la cancillería en la donación a Lugo del octubre anterior, y es también idéntica la intitulación de ambos. Más llamativo aún resulta encontrar una motivación muy similar a la de los documentos de 1150: la semejanza es tanta que resulta difícil creer que dichos textos no se tuvieran ahora a la vista, según lo atestigua la comparación en el cuadro 2.

\section{CUADRO № 2}

\begin{tabular}{|l|l|}
\hline Oviedo 1154 & Lugo 1154 \\
\hline uidens Ouetensem ecclesiam & uidens Lucensem aecclesiam, \\
Lucensem etiam in magna & Ouetensem et Auriensem in \\
fatigatione positas hob & magna fatigacione positas \\
discordiam que diu inter & hob discordiam que diu \\
ipsas exagitabatur, quia & inter ipsas exagitabatur, \\
michi a Deo et a sede & quia mihi a Deo et a sede \\
apostolica in penitenciam et & apostolica in penitentiam et \\
in remissionem peccatorum & in remissionem peccatorum \\
meorum commissum est ut & meorum comissum est ut \\
ecclesias Dei diligam et inter & aecclesias Dei diligam et inter \\
eas pacem reformem, & eas pacem reformem, \\
\hline
\end{tabular}

Pero al mismo tiempo, otros indicios textuales permiten creer que el trabajo de la cancillería está mediatizado por el destinatario, y que el obispo de Lugo impulsaba la adición a su privilegio de algunas cláusulas que, en la forma en que nos ha llegado la concesión a Oviedo, no aparecen. Se trata de la insistencia en el valor de lo escrito "ad retinendam memoriam, ad seruandam firmitatis pacem ne ullo unquam temporis interuallo controuersia ualeat pullulare». O bien de la calificación del documento, a la hora de datarlo, como "carta et pacis concordia», mucho más de la simple carta que figuraba en la versión ovetense. Se aplicaría así a la cancillería leonesa la posibilidad de que los destinatarios median en la redacción de los documentos, motivando la inclusión de determinadas cláusulas.

47 Sobre esta reunión y el arreglo del conflicto entre las diócesis como objetivo, con bibliografía previa, vid. Fita 1894.

48 Reilly 1974: 72. Aún así no tiene presencia legatina, y por lo tanto no figura en la lista de Fletcher 1994: 488-489. 


\section{EL PACTO ENTRE LAS DIÓCESIS}

Tras la intervención regia, quedaba por formalizar el pacto entre las sedes. La preocupación por hacerlo, y por dejarlo escrito, también venía de atrás y se había postergado durante años. En 1150, en su donación a Orense, declara el Emperador que ya había intentado algo similar, además con un detalle inusual: "promisit et concessit mihi ut iret domnus Martinus, Auriensis episcopus, ad aecclesiam Sancti Saluatoris de Oueto et ipse supradictus domnus Martinus, Ouetensis aepiscopus, faceret kartam de omnibus aecclesie Sancti Saluatoris canonicis roboratam».

Aquella promesa no se había cumplido. Pero ahora, en el pleito con Lugo, el documento formal sí llegó (doc. 7). Hasta la actualidad, el texto era conocido mediante copias cartularizadas en ambas sedes, la de Lugo en el siglo XIII, la de Oviedo a fines del XIV. Sin embargo, el archivo catedralicio lucense ha conservado también dos pergaminos sueltos que lo transmiten, uno de ellos original, el otro copia poco posterior en el tiempo que se empeña en corregir al primero. Ambos textos solucionan algunos problemas de lectura de las copias conocidas hasta ahora, y sobre todo facilitan un estudio más detallado de la génesis del documento.

A la altura de 1154 ambas sedes eran ya veteranas en el recurso a la escritura para la plasmación de sus privilegios, aunque la separación entre una oficina episcopal y otra capitular aún quedaba lejos. ${ }^{49}$ En Lugo, la presencia de algunos maestros franceses ${ }^{50}$ está acompañada por la existencia - fugaz - de un notario episcopal ya desde $1122,{ }^{51}$ y algunas suscripciones episcopales portan un signo rodado que copia la divisa de Pascual II..$^{52}$ La sede ovetense, por su parte, había protagonizado una de las experiencias de cartularización más ricas de principios del siglo $X I I,{ }^{53}$ y presidía entonces la diócesis el obispo Martín, que concurrió al concilio de Reims en 1148 -donde recibió la reprimenda de Eugenio III- y actuó como juez delegado en algunas causas; ${ }^{54}$ en su época, la presencia de un tal Iterius como magister en el cabildo habla también de las verosímiles relaciones exteriores que la diócesis mantiene. ${ }^{55}$

Todas aquellas novedades, sin embargo, no habían llevado aún en ninguna de las dos sedes a la creación de una oficina estable con títulos fijos, actuación permanente y formas diplomáticas homogéneas. Esa fugacidad se advierte en el hecho de que el presunto responsable de su escrituración, el canónigo lucense Pedro Miguélez, figura aún perdido en la larga lista de confirmantes y no expresa iussio alguna. De ese modo es también fácil comprender los titubeos que se muestran en la expresión de su oficio: notarius episcopi en el original, pero cancellarius episcopi en la copia más próxima en el tiempo. Con semejante título sería

49 En el mismo sentido, en referencia al caso burgalés, Ostos Salcedo 1995: 430

50 D’Emilio 2008: 202.

51 Episcopi notarius PELAGIVS notuit (Archivo Histórico Nacional, Clero, 1325C, no 10).

52 Eitel 1914: 307; Pardo Rodríguez 1999: 243.

53 Sanz Fuentes 2014. Figura en una de sus miniaturas un magister Ivo.

54 Fletcher 1977: 337-338.

55 García Larragueta 1962: 414. uno de los primeros que se reconocen en el reino. ${ }^{56}$ Pero también es cierto que no vuelve a aparecer tal intitulación: no lo hace en ninguno de los otros cuatro documentos que personaje homónimo hizo por aquellos años para el obispo de Lugo, ${ }^{57}$ y encontramos que otros diplomas redactados pocos meses después llevan a otros personajes como rogatarios. ${ }^{58}$ En Oviedo, la situación no parece mejor: de los dos documentos conocidos que intitula el obispo Martín, uno de ellos tiene por rogatario a un monje del monasterio de San Vicente, y solo el segundo, la delimitación del arcedianato de Oviedo, destaca como primer documento solemne episcopal ovetense, pero sin identificar con claridad nombre ni oficio de su autor. ${ }^{59}$

La comparación de los dos pergaminos sueltos localizados en el archivo de la catedral de Lugo abre la puerta a una mejor comprensión de la génesis de estos documentos. El primero de ellos se expresa en una escritura carolina trazada con agilidad, que ocupa intensivamente la superficie del pergamino y ofrece toda la apariencia de ser un original, confirmada por el hecho de que es el único que se expresa en forma de quirógrafo. Su autor jerarquiza bien el texto mediante la puntuación y las mayúsculas, y hasta emplea recursos gráficos de calidad; ${ }^{60}$ tiene también algunos rasgos singulares como el arco muy cerrado de la $h$, y no faltan en él las correcciones a modo de tachaduras y añadidos. ${ }^{61}$ Son asimismo frecuentes los errores y las incorrecciones léxicas y ortográficas, que en última instancia evidencian una redacción precipitada.

No hemos localizado, por desgracia, la mano de su autor material en el rico fondo de pergaminos de la época que, procedentes de la catedral lucense, se conservan en el Archivo Histórico Nacional. Su escritura no se corresponde con la del escribano homónimo que suscribe otras piezas cercanas en el tiempo, de modo que hay que suponer que el canciller Pedro, al servicio del obispo, dicta el documento sin ser su autor material. Pero todo parece indicar que se trata de la pieza primigenia que estableció el texto que regularía la relación entre las partes. Y es posible imaginar que, en la ocasión solemne de arreglo entre ellas, así quedó el documento. Esto explicaría también que las suscripciones de los capitulares no fuesen autógrafas,

56 Fletcher 1978: 98, que solo cita este documento por las copias ovetenses y valora la posibilidad de un error del copista que, a la vista de los originales lucenses, no es tal. Subraya la rareza del título en el siglo XII Tock 1991: 4.

57 Además es distinta la escritura y el tenor documental de lo que en 1156 suscribe Petrus notuit (Archivo Histórico Nacional, Clero, carp. 1325D, no 14) o del Petrus notuit que escritura una venta en 1168 (Archivo Histórico Nacional, Clero, carp. 1325E, no 18). Cfr. D’Emilio 2003: 382. Casos similares de inestabilidad aparecen en Burgos (Ostos Salcedo 1995: 434), Zaragoza (Pueyo Colomina 2014: 140) o Arras (Tock 1991: 73-74).

58 Así en enero de 1155, cuando el obispo y cabildo de Lugo resuelven sus diferencias con el burgués Ramdelost, suscribe Gvtterrius qui notuit (Archivo Histórico Nacional, Clero, carp. 1325D, no 9).

59 Sanz Fuentes 1995b: 469.

60 En la primera línea, consueuerunt se resuelve con un nexo final entre $N$ mayúscula y $t$ que sale de su trazo final a la izquierda. Al principio también acostumbra a trazar la abreviatura de -um a modo de $s$ de doble curva atravesada por un trazo oblicuo. Otras veces emplea rasgos arcaicos, como la abreviatura ts para los testigos de tradición visigótica que se expresa con la forma visigótica a modo de beta invertida.

61 L4 gloriosissimus; L22 C>r<apulatus. 
como acostumbraría a ocurrir en este tipo de negocios en las décadas siguientes. ${ }^{62}$

Luego vendrían los arreglos, que refleja bien el otro pergamino lucense y los cartularios ovetenses. Frente al original, el segundo pergamino de la catedral de Lugo presenta una escritura de apariencia más libraria, trazado contrastado e indicios de gotización ${ }^{63}$ que, sin alejarlo mucho en el tiempo, ${ }^{64}$ evidencian que se trata de una copia. Lo más singular, en cualquier caso, es el empeño de su autor, que suscribe como "Guterrus Sancii qui notuit», en corregir la pieza que le sirve de modelo. No se trata de correcciones de fondo, pues el tenor documental no se altera en ninguna parte significativa. Existe sin embargo un deseo de mejorar su expresión y conseguir un resultado más formalizado y solemne.

Lo más paradójico e interesante es que las copias ovetenses no se basaron en el quirógrafo original, sino en la versión mejorada que refleja este segundo modelo, según lo acredita en primer lugar el orden de los confirmantes. Es cierto que su tradición documental resulta más compleja. Los textos ovetenses se conocen a través de dos cartularios formados a finales del siglo XIV a instancias del obispo don Gutierre $^{65}$. El primero de ellos, el llamado Libro de los privilegios, se basa en una serie de copias certificadas notariales realizadas en 1382-1383. La Regla colorada, realizada poco después, es una copia de mejor factura ejecutada para el obispo por Juan Fernández, notario de Oviedo, en 1384. Pero en cualquier caso, numerosos detalles acreditan que esta familia de copias tiene como punto de partida un texto similar al de la copia B de Lugo. Y es verosímil pensar, por lo tanto, que al quirógrafo que fijó el acuerdo siguió una redacción más formalizada que llegó también a los archivos de ambas instituciones y fue tenida por prioritaria. Sin data tópica, la expresión literal de que el documento legere audiuimus in utriusque ecclesie capitulo obliga a esa redacción en diferido.

En lo que hace a la estructura documental, ninguna de las copias conocidas hasta ahora había transmitido la leyenda del quirógrafo. A partir de ahí, sin invocación de ningún tipo, ${ }^{66}$ el documento arranca con un extenso preámbulo diplomático, que continúa una práctica ya documentada en algunos pergaminos lucenses de los años treinta. ${ }^{67}$ Intitulan los obispos, que expresan precozmente su voluntad de poner por escrito la resolución de su controversia, sub cyrografi. ${ }^{68}$ Sigue así un largo expositivo en el que narra el concilio de Salamanca presidido por el Emperador, y se pasa revista a los prelados allí presentes, amén de los innumerables magnates, ya no relacionados. ${ }^{69}$ A continuación, se evoca la cesión regia a Oviedo de las jurisdicciones de Suarón y Las Regueras, y la confirmación paralela a Lugo de los territorios en disputa. A partir de ahí, cada una de las partes renuncia a sus reivindicaciones pretéritas, y se lanza una extensa maldición espiritual y pecuniaria, aspecto este último que no es habitual en otros documentos episcopales. ${ }^{70}$ Es singular la calificación diplomática del documento, serie conuencionis seu diffinicionis. Pero sobre todo destaca un léxico raro hasta entonces - diaboli consilio, diffinitio-, una fraseología renovada, y unos aires del cursus pontificio que eran inéditos en arreglos previos entre otras sedes.

Del mismo modo, los medios de validación expresan novedades en el contexto del documento eclesiástico leonés de su tiempo, pero tampoco llegan a suponer el arranque definitivo de las cancillerías episcopales y capitulares. En aquel tiempo el rey castellano ya empleaba sello, y es posible que lo apusiera cuatro años atrás en el privilegio concedido a Lugo. Del mismo modo habían empezado a utilizarlo el arzobispo de Braga o los obispos de Oporto, Palencia o Burgos. ${ }^{71}$ Pero en 1154 el prelado lucense aún no lo emplea, y no tenemos noticias de sello episcopal hasta el año 1171, siendo en cualquier caso de los más tempranos del reino. ${ }^{72}$ En Oviedo, su aparición parece retrasarse hasta principios del siglo XIII. ${ }^{73}$

Por lo tanto, la validación de este acuerdo entre las diócesis se edifica sobre tres bases. La primera es la acumulación de confirmantes, sumando un amplio y poco común repertorio de capitulares de ambas sedes que anticipa una práctica habitual en décadas sucesivas en los cabildos del reino. Debe destacarse de todos modos la singularidad de que aún se trata de una lista de nombres trazada por una misma mano, que contrasta con las suscripciones autógrafas que se hacen comunes en muchos negocios capitulares de las décadas siguientes. ${ }^{74}$

La segunda es el signo, que entonces era el modo habitual de validar los documentos episcopales. ${ }^{75}$ Lo llamativo es que ambos obispos emplean el mismo diseño, a saber la mano que porta un báculo en miniatura, con la única diferencia de su disposición en distinto sentido, girado noventa grados uno respecto al otro. ${ }^{76} \mathrm{El}$ empleo de la mano como signo de validación no era nuevo. Lo venían usando los obispos de Oviedo al menos desde los tiempos de don Pelayo, que en 1113 signa con una mano portando una tetrapétala que lleva inscrita una cruz. ${ }^{77}$ A partir de ese momento, el signo de los prelados ovetenses es una mano abierta con el símbolo de cada sucesivo obispo, que para Martín fue un báculo. ${ }^{78}$ En efecto, tenemos noticia de otros documentos

\footnotetext{
62 El primer caso en Braga data de [1114] (Cunha 2005: 147).

63 Hay algunas $s$ de doble curva a final de palabra, y no falta la fusión de curvas contrapuestas o la $d$ uncial.

64 Aun siendo manos distintas, no está lejos en el corte de la pluma y el trazado de la s final del Petrus notuit que en 1158 suscribe en Archivo Histórico Nacional, Clero, 1325D, no 16.

65 Sobre los mismos, vid. Rodríguez Díaz 1992.

66 Por la misma época desaparece en Zaragoza (Pueyo Colomina 2014: 158) o Burgos (Ostos Salcedo 1995: 440); también es rara en Braga u Oporto (Cunha 2005: 302).

67 Fletcher 1978: 118.

68 En una expresión rarísima en el tenor documental, como indica Martín López 1994-1995: 842.

69 Son típicos de documentos judiciales en otras escribanías episcopales como Braga (Cunha 2005: 341) o Arras (Tock 1991: 121).
}

\footnotetext{
70 Subraya la nula influencia pontificia en las sanctiones bracarenses Cunha 2005: 350

71 Cunha 2005: 151; Pueyo Colomina 2014: 153; Ostos Salcedo 1995: 437.

72 Archivo Histórico Nacional, Clero, carp. 1325E, n 25.

73 Sanz Fuentes 1995b: 469-470.

74 Se ha referido a algunas de ellas Camino Martínez 2010: 208-209.

75 Fletcher 1978: 107.

76 Sobre el sentido de la mano en la plástica románica, también como signo de validación, vid. Miguélez Cavero 2010: 137-147.

77 García Larragueta 1962: 351-352.

78 Sanz Fuentes 1995b: 468.
} 
signados en nombre del obispo Martín con modelo similar, aunque mejor factura. ${ }^{79}$

En la sede lucense, su empleo resulta más errático. Los tradicionales signos del obispo Pedro, a principios del siglo XII, empleaban motivos personales de tradición altomedieval. ${ }^{80}$ Luego, la influencia pontificia se deja sentir pronto cuando vemos al obispo Guido usando como signo la rota, unas veces simplemente con su nombre, ${ }^{81}$ otras con la divisa de Pascual II, muy probablemente por influencia compostelana. Sin embargo, ahora Juan vuelve a un signo menos avanzado. Habría de pasar solo un año para que retomase el empleo de la rueda de tradición pontificia, ${ }^{82}$ pero a la altura de 1154 este antiguo abad de Samos se inclina por un modelo más tradicional y sobre todo certifica la escasa institucionalización de una oficina de escritura en el entorno episcopal y la provisionalidad con que se adoptan las novedades diplomáticas. En enero de 1155 ese modelo de mano que sostiene el báculo va precedida por una forma floreada en la que se inscribe su nombre, lohannes, ${ }^{83}$ signo que volvería a usar en alguna ocasión años después; ${ }^{84}$ otras veces emplea la tetrapétala. ${ }^{85}$ En suma, no acababa de definirse en Lugo un signo episcopal que no cambiara a cada nuevo titular.

Por último, se recurre al empleo del quirógrafo, que tampoco era nuevo en ninguna de las sedes. ${ }^{86}$ El ejemplar conservado tiene en su parte superior un corte vagamente ondulado en el que queda, volteada con respecto al sentido del texto, la parte superior de una leyenda de morfología capital románica. En ella el aspecto ornamental pasa por la duplicación de trazos, el relleno entintado de otros, y las terminaciones en roleo o espátula. Su texto, de intención conminatoria, también tiene paralelos en algún otro ejemplo contemporáneo de su ámbito de producción. ${ }^{87}$

79 El primero de ellos es una permuta con el monasterio de San Vicente de Oviedo cuyo rogatario es precisamente un miembro de esta comunidad, Martinus monacus (Archivo del Monasterio de San Pelayo de Oviedo, Fondo de San Vicente, no 369). El segundo procede de San Isidoro de León, está fechado en 1148 (Archivo de la Colegiata de San Isidoro de León, no 146). También se reproduce en el Tumbo de Samos, que copia su cartula libertatis de 1150 (Apéndice, doc. 4).

80 Así en 1113 (Archivo Histórico Nacional, Clero, carp. 1325C, no 4) o 1122 (Archivo Histórico Nacional, Clero, carp. 1325C, no 10).

81 Así en 1137 (Archivo Histórico Nacional, Clero, carp. 1325C, no 22bis) o 1147 (Archivo Histórico Nacional, Clero, carp. 1325D, no 2). Cfr. Eitel 1914: 307; D’Emilio 2003: 386.

82 Lo hace de forma errática, pues en 1158 aparece inscrito en una tetrapétala su nombre como episcopus lohannes (Archivo Histórico Nacional, Clero, carp. 1325D, nos. 17 y 18), motivo sobre el que sigue evolucionando en años siguientes (Archivo Histórico Nacional, Clero, carp. 1325E, no 2, de 1162). En 1168 vuelve a signar con una rueda, dibujada ahora en torno a una cruz procesional con alfa y omega, y cuya leyenda reza Signvm lohannis Lucensis episcopi (Archivo Histórico Nacional, Clero, carp. 1325E, no 17).

83 Archivo Histórico Nacional, Clero, carp. 1325D, no 9.

${ }_{84}$ Por ejemplo en 1168, cuando vende al burgués Vermudo Pérez una cortina por setenta sueldos (Archivo Histórico Nacional, Clero, carp. 1325E, no 18$)$.

85 Fletcher 1978: 110, en Archivo Histórico Nacional, Clero, carp. 1325D, nos. 17 y 18.

86 En Oviedo ya lo usa el ejemplo citado de 1113 (García Larragueta 1962: 351-352). En Braga el primer ejemplo conocido se retrasa hasta 1155 (Cunha 2005: 303). Cfr. Fletcher 1978: 111.

87 La permuta del obispo Martín de Oviedo con el monasterio de San Vicente en 1149 se cortaba en línea recta por la leyenda NEC MUTENTUR, ejecutada con recursos gráficos bastante similares a los del
Pero en cualquier caso destaca la temprana conciencia de su valor probatorio al incluirlo en el tenor documental, precisamente con su denominación de cyrografi. Aunque tenía sus riesgos, como recuerda algún pleito algo posterior, ${ }^{88}$ hay que subrayar que quizá es el mejor y principal medio de validación, y que tardarían los sellos en imponerse en la conciencia de la época. ${ }^{89}$

\section{EL REFRENDO PONTIFICIO}

Resuelto el conflicto, el papel del pontífice parece limitarse a refrendar un acuerdo que se había alcanzado localmente. Dicho refrendo se expresa a través de dos documentos expedidos con pocos meses de diferencia. EI primero de ellos, muy deteriorado, lo intitula Adriano IV (1154-1159) en Narni el 17 de agosto de 1156 (doc. 8), y responde en todo a los caracteres del privilegio solemne según se venía haciendo desde la época de Inocencio II:90 letras agrandadas en la primera línea, cierre de la dirección con la locución in perpetuum, repetición por tres veces de la aprecación amen al final del texto, suscripción del pontífice, rota, suscripción de los cardenales, data extensa con referencia al funcionario que la apone y bula de plomo pendiente de hilos de seda; no hay huellas de que haya llevado monograma. Tras un preámbulo en el que expone la obligación pontificia de administrar justicia entre las diócesis, confirma su protección a la Iglesia de Lugo retrotrayendo su extensión a sus antiguos términos según se contenían en los privilegios de sus antecesores Urbano, Pascual, Inocencio y Calixto, a saber Nauiam uidelicet, Valongam, Flamosam, Neiram, Sarriam, Froilanos, Parmam, Sau[nnos, Lemos, Verosma, Asmam Auiancos], Cambam, Deza; en suma, los mismos términos acordados en el pacto entre las sedes y uno más, ya reconocido en privilegios pontificios anteriores, a saber el de Navia de Suarna. Del mismo modo confirma cuantos bienes poseyesen en esos términos, así como las donaciones de Raimundo y Urraca. Todo ello se valida con sello de plomo pendiente de hilos de seda, que se ha conservado.

El mismo Adriano IV intitula un nuevo documento para Lugo el 2 de agosto de 1157 (doc. 9), pero ahora las litterae notabiliores ya solo expresan el nombre del pontífice y falta la locución in perpetuum, por lo que sería en su aspecto formal un privilegio simple ${ }^{91}$ de cuyo sello quedan solo los hilos de los que pendía. Su contenido, sin embargo, resulta menos estereotipado y más rico que en el caso anterior. El preámbulo ya deja ver cómo discurrieron los acontecimientos cuando reconoce que es deber del Papa refrendar aquellas controversias que acaban concorditer ac pacifice aliquibus mediantibus. Así que a continuación procede a confirmar el acuerdo alcanzado entre los obispos de Lugo y Oviedo con la mediación del rey Alfonso VII, y hace referencia explícita a todas las concesiones que intervinieron en el mismo y los

documento de 1154 (Archivo del Monasterio de San Pelayo de Oviedo, Fondo de San Vicente, perg. no 369). Vid. también Martín López 19941995: 851.

88 Linehan 2009.

89 Un documento bracarense, ya en el siglo XIII, explicaba su superioridad por la fragilidad de los sellos, según cita Cunha 2005: 157.

90 Bresslau 1998: 78; Frenz 1998: 20.

91 Me remito de nuevo a la nomenclatura de Bresslau 1998: 78. 
documentos que las reflejaron: primero la donación regia de los señoríos de Suarón y Las Regueras a Oviedo, luego el acuerdo entre las sedes por las parroquias tanto tiempo en conflicto. Debe notarse que Navia de Suarna de nuevo no se cita; y sobre todo es muy revelador el orden en que aparecen estos territorios: no es el que había empleado el mismo Adriano IV en su bula de 1156 - por lo tanto, no hay memoria clara ni uso habitual de las propias concesiones-, sino que se toma directamente del acuerdo entre Oviedo y Lugo, del cual se extraen también los hitos que las delimitan, correspondientes a la zona de Fonsagrada. Más allá de eso, se toman del documento episcopal expresiones inéditas en la documentación pontificia: el facto scripto, firmato uerbo, adstricto pacto, ueritate asstructa de la concordia de 1154 se expresaba en la bula de 1157 como facto similiter scripto, uerbo firmato et pacto astricto. En definitiva, la cancillería del papa se dejaba llevar por el modelo recibido renunciando a generar un discurso propio. Los errores, como leer Vilonem donde decía Nilonem, declaran unos instrumentos donde quizá pesaba más la autoridad del intitulante que la exactitud del contenido.

Los documentos pontificios venían así a cerrar un conflicto y fijarlo por escrito con intención perpetua, para que nunca se olvidase. El precio del arreglo tuvo que ser alto. Primero los 300 maravedíes a Alfonso VII en 1150, y aún más que no sabemos con certeza; en 1168 otro documento nos informa casualmente de que se iban a emplear 50 sueldos para el pago del arreglo con Oviedo: «quorum $L \underline{a}$ dedi in determinatione nostra et Ouetensis sedis"; aunque no dice que se hayan gastado expresamente en tasas, queda claro que el arreglo se estaba pagando, y bien. ${ }^{92}$ Y como tenía que haber compensaciones para todos, sería creíble que se pudiera enmarcar en este contexto la concesión de Adriano IV en 1157 por la que Oviedo recuperaba su exención, ${ }^{93}$ que sólo había disfrutado efímeramente en 1105-1111, período tras el que estuvo sometida a Toledo. Luego Alejandro III volvería a confirmar dicha exención en $1162 .{ }^{94}$

Es mucha la insistencia en este asunto, y traía a la Península Ibérica nociones nuevas: de documentos auténticos, de formalización de los derechos a través de la escritura legítima. De este modo se iniciaba una larga serie de documentos pontificios en el archivo de Lugo que refrendan y repiten cansinamente lo ya conocido, ${ }^{95}$ y que merecerían en sí mismos otro estudio sobre su variación en el tiempo, pero que desbordan ya las intenciones de este trabajo.

\section{CONCLUSIONES}

En una época en la que la debilidad del Papado aconsejaba una política de negociaciones y acuerdos con el rey de Castilla ${ }^{96}$, las delimitaciones de las diócesis constituyen un observatorio revelador sobre la naturaleza de aquellas

92 "...in determinatione nostra et Ouetensis sedis» (Archivo Histórico Nacional, Clero, carp. 1325E, no 18, cit. D’Emilio 2008: 205; ed. Cañizares del Rey 2014: 342).

93 García Larragueta 1962: 416-417.

94 Ibídem: 435-436.

95 Archivo de la Catedral de Lugo, Pontificios, leg. 3, no 8. Tres documentos confirmatorios de Alejandro III en López Sangil y Vidán Torreira 2011: 186-192.

96 Ayala Martínez 2017: 261-268. relaciones, y la forma documental en que se expresan manifiesta igualmente las influencias recíprocas entre las partes implicadas en el conflicto. Desde luego los problemas de límites continuaron; en 1185 estallaba el conflicto por cuestiones similares entre Lugo y Orense. Pero a estas alturas la resolución iba a ser muy distinta: Lucio III encomendaba el arreglo a los obispos de Oporto y Ávila en el marco cada vez mejor codificado del Derecho nuevo ${ }^{97}$.

Por el contrario, lo que representa la delimitación entre Oviedo y Lugo en los años cincuenta supone un punto medio entre los procedimientos tradicionales de negociación, mediación y cesiones mutuas, y la novedad de procedimientos escritos cada vez mejor regulados en un circuito documental constante. Un conflicto de límites arrastrado durante décadas tuvo en la redacción de documentos diplomáticos una de sus armas fundamentales, y también encontró en ellos el vehículo para su solución final. En la cancillería regia se detectan influencias entre distintos documentos, y también la adaptación de sus fórmulas a los destinatarios: por un lado parece entreverse el empleo de documentos previos como modelo textual, y por otro la intervención de los destinatarios en los matices redaccionales de los documentos expedidos. Luego, otras evidencias de este corpus documental ayudan a comprender mejor la vida de los documentos después de su primera redacción. La posibilidad de seguir la tradición diplomática del acuerdo entre las sedes de Lugo y Oviedo acredita que, en la segunda mitad del siglo XII, un quirógrafo podía ser copiado y que aquella copia mejorada prevalecía durante siglos como la que mejor reflejaba el tenor del acuerdo, por encima de la carta partida originaria. En fin, acabado el conflicto todo el dosier de documentos llegó a la vista de Adriano IV, quien confirma el acuerdo haciendo referencia explícita a los documentos antecedentes. $Y$ es interesante subrayar aquí que la cancillería pontificia parece recibir textos que incorpora directamente a sus privilegios, incluso con errores derivados de una lectura deficiente; pero que aún así esos privilegios son conservados durante siglos como fuente de autoridad. De todo ello también se concluye que, en ese circuito documental cada vez más complejo no es fácil aclarar el sentido de las influencias, ni asegurar la existencia de préstamos directos y voluntarios en dirección unívoca. ${ }^{98}$ La inestabilidad en las oficinas episcopales dejaba un amplio margen de maniobra a los rogatarios e impide hacer generalizaciones sobre lo que son más bien formulaciones particulares fruto de un sincretismo como el que se aprecia en la documentación episcopal inglesa desde los años cuarenta del siglo XII. ${ }^{99} \mathrm{EI}$ hecho de que al cardenal Jacinto, en 1155 , no le quedase más tarea que refrendar el arreglo que se había hecho a escala local, declara con rotundidad los límites de la influencia pontificia en el reino castellano-leonés.

\footnotetext{
97 Cañizares del Rey 2014: 405.

98 En tal sentido, Guyotjeannin 1993: 86.

99 Cheney 1950: 71-72. La mezcla se ve muy bien en una venta al juez Pelayo de 1148, que lo mismo tiene preámbulo de memoria muy moderno que cita la ley visigótica con soltura (Archivo Histórico Nacional, Clero, 1325D, no 5).
} 


\section{EDICIÓN DIPLOMÁTICA}

1

1150, febrero, 21. Peral de Arlanza.

Alfonso VII dona a la Iglesia de Lugo los territorios que esta sede venía disputando con Oviedo, a cambio de 300 maravedís y de otra cantidad consignada en un documento anterior, que se hará efectiva cuando Oviedo entregue finalmente los territorios en disputa.

\begin{abstract}
A.- Pergamino, $68 \times 35,7 \mathrm{~cm}$. Carece de plica, pero presenta tres orificios en disposición triangular de los que debió pender un sello.

Archivo de la Catedral de Lugo, 1.10.3.

Ed.: M. Risco, España Sagrada, vol. XLI, Madrid, 1798, ap. VIII, pp. 309-310.- F. Fita: «Concilios de Salamanca y Valladolid», pp. 460-462.- F. Vázquez Saco, «Un diploma de Alfonso VII", Boletín de la Comisión provincial de monumentos históricos y artísticos de Lugo, II (1947), pp. 285-298.- M. Recuero Astray e.a., Documentos medievales del reino de Galicia: Alfonso VII (1116-1157), Santiago de Compostela, 1998, no 132, pp. 139-140.

Reg.: P. Rassow, «Die Urkunden Kaiser Alfons'VII. von Spanien. Eine palaeographisch-diplomatische Untersuchung", Archiv für Urkundenforschung, X/3 (1928), pp. 328-467 y XI/1 (1929), pp. 66-137, p. 449.- L. Sánchez Belda, Documentos reales de la Edad Media referentes a Galicia. Catálogo de los conservados en la sección Clero del Archivo Histórico Nacional, Madrid, 1953, no 252, p. 121.- M. Lucas Álvarez, El reino de León en la Alta Edad Media, V. Las cancillerías reales (1109-1230), León, 1993, no 558, p. 286.- B.F. Reilly, The Kingdom of León-Castilla under King Alfonso VII, 1126-1157, Philadelphia, 1998, p. 371.
\end{abstract}

Facs.: Vázquez Saco, "Un diploma de Alfonso VII», p. 286.

(C) In nomine Domini nostri lesu Christi. Decet inter ceteros homines regiam siue imperatoriam precipue potestatem aecclesias Dei diligere, et eis propria ecclesiastica iura, si in aliquo tempore amiserint, dare, data manutenere, uenerari et foueri. Eapropter ego Adefonsus, Dei misericordia tocius Hispanie imperator, vna cum filiis meis et omni successione mea, uidens aecclesiam Lucensem in magna fatigatione positam pro discordia que diu inter aecclesiam Ouetensem et ipsam Lucensem aecclesiam exagitabatur, quia mihi a Deo et a sede apostolica in penitencia et in remissione peccatorum meorum commissum est ut aecclesias Dei in ius $<$ ti $>$ tia regam, ideo consilio domni Raimundi, Toletani archiepiscopi et tocius Hispanie primatis, et aliorum meorum aepiscoporum fatio kartam donationis et textum firmitatis Deo et aecclesiae Sancte Marie Lucensi et uobis aepiscopo domno Guidoni et omnibus successoribus uestris de omni diocesi illa de qua discordia inter Ouetensem ecclesiam et aecclesiam uestram erat, ut nunquam ego nec filii mei nec aliquis ex generatione mea auferant uobis nec alicui successori uestro ipsam diocesim supranominatam. Et hoc fatio quia per ueritatem noui diocesim illam Lucensis ecclesiae esse debere; et accipio a uobis $\mathrm{CCC}^{\circ}$ morabitinos. Et quando ego fecero concambiationem inter Ouetensem aecclesiam et ipsam aecclesiam uestram, sicuti iam facere uolui, quod dem de propriis regalibus meis aecclesiae Ovetensy ${ }^{100}$, ut

\footnotetext{
100 La $y$ va corregida sobre $e$.
}

uos uel successor uester qui in Lucensi aecclesia in loco uestro aepiscopus fuerit, tribuat mihi uel successori meo qui in loco meo rex fuerit, illos alios morabitinos quos modo remanent, sicuti inter me et uos firmatum est, et hoc factum semper sit firmum. Si uero in posterum aliquis ex meo uel alieno genere hoc meum factum rumper<e $>$ temptauerit, sit a Deo maledictus et excomunicatus, et cum luda traditore Domini in inferno dampnatus, et insuper pariat regie parti $\mathrm{X}^{\mathrm{cm}}$ milia morabitinos.

Facta karta in uilla que uocatur Peral, anno tertio quo

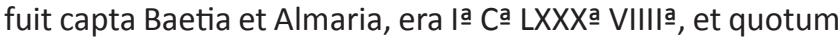
VIIIIo kalendarum marcii, inperante Adefonso imperatore in Toleto et in Legione, in Galletia et in Castella, in Nagara et in Saragocia, in Baetia et in Almaria. Garsia, rex Nauarre, tunc temporis vassallus imperatoris. Comes Barchilonensis tunc temporis uassallus imperatoris.

Ego Adefonsus imperator, hanc kartam quam fieri iussi, propria manu mea roboro atque confirmo ( $\mathrm{S}$, et in signo, SIGNVM IMPERATORIS).

(1 $\underline{a}$ col.) Rex Santius, filius imperatoris, conf.- Guter Fernandiz conf.- Comes domnus Lupus conf.- Gumez Gunzaluiz conf.

( $2^{a}$ col.) Comes domnus Poncius, maiordomus imperatoris, conf.- Arias Caluus de Castella de Buual conf.- Nunus Petriz, alferiz imperatoris, conf.- Gundisaluus Ruderiquiz conf.

lohannes Fernandiz, canonicus ecclesie beati lacobi et scriptor imperatoris, scripsit.

\section{2}

1150, marzo, 1. Burgos.

Alfonso VII dona al obispo Martín y a la catedral de Oviedo las iglesias de Santa Marina y Santa Gadea en la ciudad, según las había tenido su abuelo Alfonso VI.

B.- Noticia en inventario del siglo XVIII.

Archivo de la Catedral de Oviedo, ms. 53, Libro Maestro, vol. I, p. 10 (fecha el 25 de febrero).

Reg.: C. Miguel Vigil, Asturias monumental, epigráfica y diplomática, vol. I, Oviedo, 1887, p. 89 (del original).Lucas Álvarez, Cancillerías reales, no 521, p. 282.- Reilly, Alfonso VII, p. 371.- P. García Muñoz, La organización y descripción de un archivo catedralicio en el siglo XVIII. Estudio y edición del Libro Maestro, ms. 53 del Archivo Capitular de la Catedral de Oviedo, tesis doctoral inédita, Universidad de Oviedo, 2016, p. 4.

3

1150, marzo, 1. Burgos.

Alfonso VII, viendo que el obispo de Oviedo no había cumplido su compromiso de restituir parroquias a la diócesis de Orense, dona a su obispo Martín y a sus sucesores las parroquias que se habían pactado, recibiendo a cambio setenta marcas de plata.

A.- Pergamino, $51,8 \times 38,5 \mathrm{~cm}$.

Archivo de la Catedral de Orense, Privilexios 1, no 31. Ed.: Recuero Astray e.a., Galicia, Alfonso VII, no 129, pp. 135-136.- M.B. Vaquero Díaz y F.J. Pérez Rodríguez, Colección documental del archivo de la Catedral de Ourense, I (888-1230), León, 2010, no 25, pp. 94-96.

Reg.: E. Duro Peña: «Catálogo de documentos reales del archivo de la catedral de Orense», Miscelánea de textos medievales, 1 (1972), pp. 9-145, no 23, p. 19.- Lucas Ál- 
varez, Cancillerías reales, $\mathrm{n}$-524, p. 282.- Reilly, Alfonso VII, no 640, p. 371.

(C) In nomine Domini nostri Ihesu Christi. Decet inter ceteros homines regiam siue imperatoriam precipue potestatem, quia plura ceteris posidet, aecclesias Dei amare et unicu $>$ i<que aeclesiae propria aeclesiastica iura tribuere. Eapropter ego Adefonsus, Dei misericordia tocius Hispanie imperator, videns aeclesiam Auriensem in magna fatigatione positam pro discordia que diu inter aeclesiam Ouetensem et ipsam aeclesiam Auriensem exagitabatur, quia mihi a Deo et ad sede apostolica in penitentia commissum est ut aecclesias Dei in ius<ti>tia regam, ideo consilio domni Raimundi, Toletani archiepiscopi et tocius Hispanie primatis, et aliorum meorum aepiscoporum, feci pactum atque concordiam in Pallentia, in presentia istorum supradictorum, inter domnum Martinum, Auriensem aepiscopum, et Martinum, Ouetensem aepiscopum, ut darem aeclesiae Sancti Saluatoris de Oueto illud castellum de Goela cum Laviana pro hereditate per cartam. Et ipse domnus Martinus, Ouetensis episcopus, cum quadam parte de melioribus canonicis tocius eclesiae Sancti Saluatoris qui tunc ibi aderant, scilicet cum Didaco Nuniz, qui tunc erat prior in Ouetensi aeclesia, et cum Aluaro priore, et cum archidiacono lohanne Falcum, et cum Gundisaluo archidiacono, et cum archidiacono Petro Pardo, et cum Petro Mariscot, archidiacono, et cum Iuliano capellano, et cum Martino Olaliz et cum ceteris alliis qui ibi erant, promisit et concessit mihi ut iret domnus Martinus, Auriensis episcopus, ad aeclesiam Sancti Saluatoris de Oueto et ipse supradictus domnus Martinus, Ouetensis aepiscopus, faceret kartam de omnibus aeclesie Sancti Saluatoris canonicis roboratam ut dimmitteret eclesiae Auriensi totam diocesim de Limia ad Monte Barone usque ad Doniam, et de fluuio de Zor usque ad Arnuiam sicuti intrat in flumine Minei, et usque ad Barrosum, cum aeclesiis de Petraiu, et Castellam cum illis aeclesiis de Urzilum et cum Sancto lohanne de Penna Cornaria, cum aeclesiis de Auia et de Auion et cum aeclesiis de Nouula. Et quod nunquam ipse supradictus domnus Martinus, Ouetensis aepiscopus, uel eius successores inquietarent Auriensem aeclesiam amplius pro omni diocesi illa supranominata, quod postea facere noluerint et de omnibus his que mihi promiserant ut facerent mentiti sunt. Et quia quod mihi per ueritatem promiserunt facere noluerunt, ideo ego supradictus Adefonsus imperator, pro me et pro filiis meis et pro omni generatione mea, quia per ueritatem noui diocesim illam supranominatam iuris aeclesie Auriensis antiquitus fuisse, fatio kartam donationis et textum firmitatis Deo et aeclesie Sancti Martini de Aurenis et uobis domno Martino, Auriensi aepiscopo et omnibus uestris successoribus, de diocesi illa superius nominata tali pacto, ut nunquam ego nec aliquis ex progenie mea tribuam di[ocesim] illam Ouetensi aeclesiae, et accipio a uobis LXXa mar $<c>$ has argenti. Et quando ego uel aliquis ex generatione mea hanc concambiationem inter aeclesiam Ouetensem et Auriensem aecclesiam fecero, quod uos domnus Martinus, Auriensis aepiscopus, uel qui in loco uestro [in Auriense] aeclesia aepiscopus fuerit, tribuat mihi uel qui in regno meo rex fuerit illas $L X X X X^{101}$ marchas que modo remanent, et hoc factum semper sit firmum. Si uero in posterum aliquis ex

\footnotetext{
101 Parece que la última $X$ fue añadida con posterioridad.
}

meo uel alieno genere hoc meum factum rumpere temptauerit, sit a Deo maledictus et excomunicatus et cum luda, traditore Domini, in inferno dampnatus, et insuper pariat regie parti $X^{\mathrm{em}}$ milia morabitinos.

Facta karta in ciuitate Burgis, anno tercio quo fuit capta Baetia et Almaria, era Iㅁ Ca LXXXo VIII $\underline{\text { a }}$, et quotum die kalendarum marcii, inperante Adefonso imperatore in Toleto et in Legione, in Galletia et in Castella, in Nagara et in Saragotia, in Baetia et in Almaria. Garsia, rex Nauarre, tunc temporis uassallus imperatoris. Comes Barchilonensis tunc temporis uassallus imperatoris.

Ego Adefonsus imperator, hanc kartam quam fieri iussi propria manu mea roboro atque confirmo.

(1모 col.) Rex Santius, filius imperatoris, conf.- Garsia, rex Nauarre, conf.- Guter Fernandiz conf.- Comes domnus Lupus conf.

(S, et in signo, SIGNVM IMPERATORIS).

( $2^{a}$ col.) Domnus Uictorius, Burgensis aepiscopus, conf.Comes domnus Poncius, maiordomus imperatoris, conf.Gumiz Gunzaluiz conf.- Nunus Petriz, alferiz imperatoris, conf.

Iohannes Fernandiz, canonicus eclesiae Beati lacobi et scriptor imperatoris, scripsit.

\section{4}

1150, marzo, 1.

El obispo Martín II de Oviedo, aconsejado por el rey Alfonso VII y por el primado Raimundo, renuncia al ejercicio del derecho episcopal sobre el monasterio de Samos y todas sus iglesias.

B.- Copia en cartulario de principios del siglo XIII.

Archivo de la Universidad de Santiago de Compostela, Clero, 1173, fols. 21r-v.

Ed.: Lucas Álvarez, Tumbo de Samos, no 50, pp. 148-149.

Sub Christi nomine. Ego Martinus, Dei gratia II ${ }^{\mathrm{s}}$ Ouetensis episcopus, consilio adunante et uoluntate concordante archidiaconorum et canonicorum eiusdem ecclesie et consilio imperatoris domni Adefonsi atque dispositione primatis Toletani cui a domino Apostolico commissa est potestas in ecclesiis totius Hispanie, tibi abbati Samonensi eiusdem loci sancti fratrum congregationi atque successoribus uestris facimus scriptum libertatis ut amplius Samonense monasterium aut ecclesias uestras siue intra cautum siue extra cautum ad Samonense monasterium pertinentes non inquietemus, neque ius pontificale super monasterium uestrum aut super ecclesias uestras unquam requiramus, et episcopum qui uobis in rebus ecclesiasticis ministrauerit non inquietabimus, et ad quemcumque episcopus uobis placuerit eundi licentiam a nobis in perpetuum habeatis.

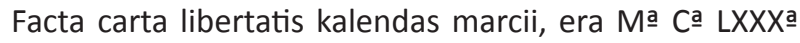
VIIIa, imperante imperatore domno Adefonso Almaria, Baecia, Tholeto et Legione.

Ego Martinus, Ouetensis episcopus, hanc cartam roboramus (S). Didacus, archidiaconus et canonice prior, conf. Icterius, magister scole, conf. lohannes, Salamanticensis episcopus, conf. Petrus, archidiaconus, conf. Gundissaluus, archidiaconus, conf. Ciprianus, abbas thesaurarius, conf. lohannes, primiclerus, conf. Martinus, capellanus, conf., et omnes canonici conf. Petrus, testis. lohannes, testis. Pelagius, testis. Petrus, presbiter, notuit. 
1154, enero, 2. Salamanca.

Alfonso VII con su esposa Rica, su hermana Sancha y sus hijos Sancho y Fernando, con el encargo del Papa y el consejo de arzobispo de Toledo y los magnates del reino, dona a la Iglesia catedral de Oviedo y a su obispo Martín la jurisdicción del castillo de Suarón y de la tierra de Las Regueras para compensar los derechos perdidos por la concordia establecida con la diócesis de Lugo.

[A].- Original perdido. Descrito por B como «seellada de un seello grande pendiente, et en medio del seello seya figura de Emperador en sua cadera, sua corona en a cabeza, et de la una parte et de la otra sennas figuras de cabeças de león, et las letras de arredor el seello yeran tales: "+ S. Adefonsus imperator hispanie" [...] et demaes enna figura del Emperador tenía enna mano seniestra una piertiga semellante flor arimada al honbro, et enna mano derecha commo pella redonda». C lo describe como "seellado de un gran seello de çera colgado en una correa corçuna, e del un cabo del seello seya fegura de hun omne en una cadera, sua coronna en la cabeça e commo pella en la mano, e las letras del seello dezían así: "+ Adefonsus imperator, yspaniorum", e del otro cabo del seello non auía letra nin fegura ninguna».

[B].- Perdido. Copia certificada notarial hecha por Juan Pérez, notario público del rey en Oviedo, el 15 de octubre de 1291.

[C].- Perdido. Copia certificada notarial hecha por Juan Pérez, notario público del rey en Oviedo, el 17 de julio de 1300.

D.- Papel, copia simple de B, parcialmente figurada. Biblioteca Nacional de España, ms. 13.074, pp. 134-136.

E.- Copia certificada notarial de fines del siglo XIV hecha por Alfonso Fernández de Cabezón, notario apostólico y notario público del rey.

Archivo de la Catedral de Oviedo, ms. 4, Libro de los Privilegios, fols. $139 \mathrm{v}-140 \mathrm{v}$.

F.- Copia certificada notarial de fines del siglo XIV. Archivo de la Catedral de Oviedo, ms. 2, Regla Colorada, fols. $23 v-24 r$.

ED.: H. Flórez, España Sagrada, vol. XXXVIII, Madrid, 1793, ap. XXXIV, pp. 351-353; García Larragueta: Colección de documentos, no 162, pp. 409-411; E.E. Rodríguez Díaz, El libro de la Regla Colorada de la Catedral de Oviedo. Estudio y edición, Oviedo, 1995, no 13, pp. 335-336.

Reg.: Lucas Álvarez, Cancillerías reales, no 648, p. 298. Reilly, Alfonso VII, № 813, p. 385.

(C) In nomine Domini nostri lesu Christi. Sicut in omni contractu condiciones ualere imperialis testatur auctoritas sic etiam iustitie ratio exigit ut ea que a regibus siue ab imperatoribus fiunt scripto firmentur, ne temporum diuturnitate ea que iusta sunt obliuioni tradantur. Idcirco ego Adefonsus, Dei misericordia totius Hispaniae imperator, una cum huxore mea imperatrice domina Rica, et cum sorore mea regina domina Sancia et cum filiis meis regibus Sancio et Fernando et filiabus et omni progenie mea, uidens Ouetensem ecclesiam Lucensem etiam in magna fatigatione positas hob discordiam que diu inter ipsas exagitabatur quia michi a Deo et a sede apostolica in penitenciam et in remissionem peccatorum meorum commissum est ut ecclesias Dei diligam et inter eas pacem reformem, consilio domini
Iohannis Toletani archiepiscopi et tocius Hispanie primatis et omnium fere tocius imperii mei episcoporum, comitum atque principum, fatio cartam donationis et textum firmitatis Deo et ecclesie Sancti Saluatoris Oueti et uobis domino Martino secundo, Ouetensi episcopo, et omnibus eiusdem ecclesie successoribus uestris de illo castello de Sueirum quod est inter fluuium de Oue et fluuium de Nauia, et de illas Regarias que sunt in terra Oueti. Hec dono >et concedo< uobis per suos terminos antiquos cum omnibus hereditatibus et aquisitionibus, tam regum quam comitum uel aliorum quorumcumque hominum, et quantum ibi aquisitum et exquisitum est uel esse potuerit cum suo capite ${ }^{102}$ et cum suo sagione et cum omnibus suis directuris et calumpniis et cum omni uoce regia et cum omni sua criatione, cum omnibus istis prenominatis que infra hos terminos uel extra inuenta sunt uel esse potuerunt. Et hoc facio ad reformandam pacem et concordiam inter supradictas sedes, ut ab hac die habeatis et possideatis uos et omnes successores uestri iure hereditario in perpetuum. Si uero aliquis homo ex meo uel alieno genere hoc meum factum rumpere temptauerit, sit a Deo maledictus et excommunicatus, et cum luda proditore Domini in inferno dampnatus, et pectet ecclesie parti mille marchas argenti.

Facta carta in Salamantica, IIIIo nonas ianuarii, era Maㅡ Ca LXa II $\underline{\text { a }}$ imperante ipso imperatore Toleti, Legione, Gallecia, Castella, Nagera, Saragocia, >Baetia< et Almaria. Comes Barchilonie et Sancius, rex Nauarra, vasalli imperatoris.

Ego Adefonsus, imperator Hispanie, hanc cartam testamenti quam fieri iussi propia manu $>$ mea roboro atque< confirmo.

(1므 col.) Rex Sancius, filius imperatoris, conf.- lohannes, Toletanus archiepiscopus et Hispanie primas, conf.Uincentius, Secobiensis episcopus, conf.- Ennigus, Auilensis episcopus, conf.- Nauarrum, Salamantinus episcopus, conf.lohannes, Oxomensis episcopus, conf.- Petrus, Segontinus episcopus, conf.- Rudericus, Naiarensis episcopus, conf.Uictorius, Burgensis episcopus, conf.

( $2^{a}$ col.) Comes Almanricus, tenens Baetiam, conf.Comes Lupus conf.- Ermegaudus, comes Urgelli, conf.- Gutier Fernandiz conf.- Garcia Garciaz de Aza conf.- Garcia Gumez conf.- Nunus Petriz, alferiz imperatoris, conf.- Aluarus Petriz conf.- Gundissaluus Roderiquiz conf.- Uela Guterriz conf.

(S, et in signo, SIGNVM IMPERATORIS).

(3 col.) Comes Fernandus Gallecie conf.- Comes Rudericus Petriz conf.- Comes Pontius, maiordomus imperatoris, conf.- Comes Ranamirus Froilaz conf.- Comes Petrus Adefonsus conf.- Uermudus Petriz Gallecie conf.- Fernandus Iohannis, tenens Muntor, conf.- Aluarus Ruderiquiz conf.Pelagius Curuus conf.- Gundissaluus Fernandiz conf.

(4므 col.) Rex Fernandus, filius imperatoris, conf.- Pelagius, Ecclesie beati lacobi electus, conf.- Martinus, Auriensis episcopus, conf.- Pelagius, Tudensis episcopus, conf.- lohannes, Lucensis episcopus, conf.- Pelagius, Minduniensis episcopus, conf.- Petrus, Asturicensis episcopus, conf.- Iohannes, Legionensis episcopus, conf.- Raimundus, Palentinus episcopus, conf.- Stephanus, Zamorensis episcopus, conf.

lohannes Fernandiz, canonicus ecclesie beati lacobi et notarius imperatoris, scripsit.

\footnotetext{
102 Sic pro caritel.
} 
1154, enero, 3. Salamanca.

Alfonso VII con su esposa Rica, su hermana Sancha y sus hijos Sancho y Fernando, con el encargo del Papa y el consejo de arzobispo de Toledo y los magnates del reino, dona a la Iglesia catedral de Lugo y a su obispo Juan la jurisdicción eclesiástica que venía disputando con la diócesis de Oviedo sobre los términos de Neira, Valonga, Chamoso, Sarria, Froián, Lemos, Verosmo, Saviñao, Páramo, Asma, Camba, Deza y Abeancos.

\section{A.- Pergamino, $63 \times 46,5+5,5$ de plica. Tres orificios de forma horizontal en disposición triangular de los que pendía el sello. Pequeñas manchas de humedad que afectan ligeramente al texto. \\ Archivo de la Catedral de Lugo, 1.10. 5. \\ B.- Copia simple en cartulario del siglo XIII. Omite las suscripciones. \\ Archivo Histórico Nacional, Códices y cartularios, 1043B, fol. 18r. \\ Ed.: Recuero Astray e.a., Galicia, Alfonso VII, no 160, pp. 171-172.- López Sangil y Vidán Torreira, «Tumbo Viejo de Lugo», no 29, pp. 93-95.- Ventura Cañizares, Colec- ción diplomática, II, no 255, pp. 299-301. \\ Reg.: Pallares, Argos Divina, p. 154.- Rassow, «Die Urkunden», p. 457.- Sánchez Belda, Documentos rea- les, no 273.- Lucas Álvarez, Cancillerías reales, no 648, p. 298.- Reilly, Alfonso VII, no 813, p. 385.}

(C) In nomine Domini nostri Ihesu Christi. Sicut in omni contractu condiciones ualere imperialis testatur auctoritas, sic etiam iusticie ratio exigit ut ea que a regibus siue ab imperatoribus fiunt scripto firmentur, ne temporum diuturnitate ea que gesta sunt obbliuioni tradantur. Idcirco ego Adefonsus, Dei misericordia tocius Hispanie imperator, una cum uxore mea imperatrice domna Rica et cum sorore mea regina domna Santia et filiis meis regibus Santio et Fernando et filiabus et omni progenie mea, uidens Lucensem aecclesiam, Ouetensem et Auriensem in magna fatigacione positas hob discordiam que diu inter ipsas exagitabatur, quia mihi a Deo et a sede apostolica in penitentiam et in remissionem peccatorum meorum comissum est ut aecclesias Dei diligam et inter eas pacem reformem, consilio domni lohannis, Tholetani archiepiscopi et totius Hispanie primatis, et omnium fere totius imperii mei episcoporum, comitum atque principum, ad retinendam memoriam, ad seruandam firmitatis pacem ne ullo unquam temporis interuallo controuersia ualeat pullulare, concedo Deo et aecclesiae Sancte Marie Lucensi et uobis domno Iohanni, Lucensi aepiscopo, et omnibus successoribus uestris illos terminos perpetuo habendos super quibus inter Lucensem et Ouetensem aecclesia longo holim tempore maxima discordia fuerat, uidelicet superiorem et inferiorem Neiram, una cum Ual longa, Framosum, Sarriam, Froilanos, Lemos, Uerosmu, Sauinianos, Paramos, Asma, Camba, Dezon et Auiancos. Et ut hoc meum factum firmum et stabile semper maneat, ne Ouetensis aecclesia aduersus Lucensem aecclesiam querimoniam unquam mouere ualeat, confero de regalibus meis supradicte Ouetensi aecclesiae castellum de Suerum quod est inter fluvium de Oue et fluuium de Nauia, et de illas Regarias que sunt in terra Oueti. Hec dono et concedo Ouetensi aecclesiae per suos terminos antiquos sicut in testamento quod ei feci resonat. Si uero aliquis homo ex meo uel alieno genere istam concordiam et hoc meum bonum factum rumpere temptauerit, sit a Deo maledictus et excomunicatus, et cum luda proditore Domini in inferno dampnatus, et componat aecclesiae parti mille marchas argenti.

Facta carta et pacis concordia in Salamantica, III nonas

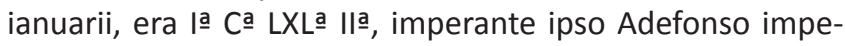
ratore Toleti, Legioni, Galletia, Castella, Naiara, Saragotia, Baetia et Almaria. Comes Barchilonie et Santius, rex Nauarre, uassalli imperatoris.

Ego Adefonsus, imperator Hispanie, hanc cartam ob pacis concordiam factam quam fieri iussi propria mea manu roboro atque confirmo.

(1ㅁ col.) Rex Santius, filius imperatoris, conf.- lohannes, Toletanus archiepiscopus et Hispanie primas, conf.Vincentius, Secobiensis aepiscopus, conf.- Ennigus, Auilensis aepiscopus, conf.- lohannes, Oxomensis aepiscopus, conf.Petrus, Segontinus aepiscopus, conf.- Rudericus, Naiarensis aepiscopus, conf.- Victorius, Burgensis aepiscopus, conf.Nunus Petriz, alferiz imperatoris, conf.

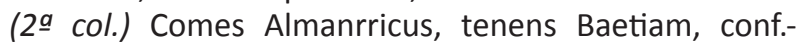
Comes Lupus conf.- Ermegaudus, comes Urgelli, conf.- Guter Fernandiz conf.- Garcia Garciaz de Aza conf.- Garcia Gaimez conf.- Aluarus Petriz conf.- Gundisaluus Ruderiguiz conf.Vela Guterriz conf.

(S, et in signo, SIGNVM IMPERATORIS).

(3ㅁ col.) Comes Fernandus Galletie conf.- Comes Rudericus Petriz conf.- Comes Pontius, maiordomus imperatoris, conf.- Comes Ranemirus Froilaz conf.- Comes Petrus Adefonsus conf.- Vermudus Petriz Galletie conf.- Fernandus Iohannis, tenens Muntor, conf.- Aluarus Ruderiguiz conf.Pelagius Curuus conf.- Gundisaluus Fernandiz conf.

(4 $\underline{a}$ col.) Rex Fernandus, filius imperatoris, conf.Pelagius, aecclesiae beati lacobi electus, conf.- Pelagius, Tudensis aepiscopus, conf.- Martinus, Auriensis aepiscopus, conf.- Pelagius, Minduniensis aepiscopus, conf.- Martinus, Ouetensis aepiscopus, conf.- Petrus, Asturicensis aepiscopus, conf.- lohannes, Legionensis aepiscopus, conf.- Raimundus, Palentinus aepiscopus, conf.- Stefanus, Zamorensis aepiscopus, conf.- Nauarro, Salamantinus aepiscopus, conf.

lohannes Fernandis, canonicus aecclesiae beati lacobi et notarius imperatoris, scripsit.

\section{7}

1154, enero, 19.

Martín, obispo de Oviedo, y Juan, obispo de Lugo, reunidos en Salamanca ante el emperador Alfonso VII, el arzobispo de Toledo y una amplia asamblea de obispos del reino, acuerdan resolver sus diferencias: el obispado de Oviedo recibe del Emperador las jurisdicciones de Suarón y Las Regueras, y a cambio renuncia a la jurisdicción eclesiástica sobre los territorios de Neira, Valonga, Chamoso, Sarria, Froián, Lemos, Verosmo, Saviñao, Páramo, Asma, Camba, Deza y Abeancos, que pasan a la diócesis de Lugo.

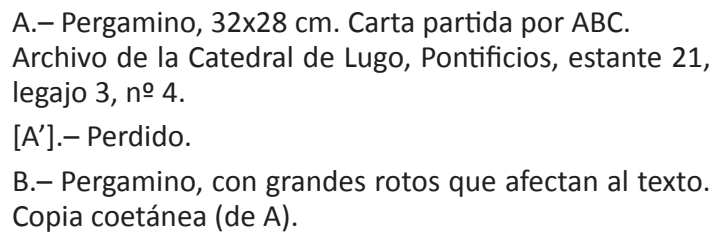


Archivo de la Catedral de Lugo, Pontificios, estante 21, legajo 3, no 3 .

C.- Copia simple en cartulario del siglo XIII (de A). Omite las suscripciones.

Archivo Histórico Nacional, Códices y cartularios, 1043B, fol. $57 \mathrm{r}-\mathrm{v}$.

D.- Copia certificada notarial de fines del siglo XIV hecha por Alfonso Fernández de Cabezón, notario apostólico y notario público del rey, y Alfonso González de León, notario público del rey (de A').

Archivo de la Catedral de Oviedo, ms. 4, Libro de los Privilegios, fols. 1-2.

E.- Copia certificada notarial de fines del siglo XIV (de $\left.A^{\prime}\right)$.

Archivo de la Catedral de Oviedo, ms. 2, Regla Colorada, fols. 24r-25v.

Ed.: Risco, España Sagrada, XLI, ap. X, pp. 312-316.Fita: "Concilios de Salamanca y Valladolid», pp. 453-458 (de E).- García Larragueta: Colección de documentos, no 163, pp. 411-414 (de E).- Rodríguez Díaz, Regla Colorada, no 14, pp. 336-339 (de E).- López Sangil y Vidán Torreira, "Tumbo Viejo de Lugo», no 113, pp. 238-241 (de B).

\section{NEC MUTENTUR SCRIPTA}

Quoniam longeuitas et longa per annorum recursus ${ }^{103}$ elapsa tempora rerum gestarum series consueuerunt abolere et uerborum ueritatem factorumque ordinem uestate ${ }^{104}$ nimia consumere, sanum duxit et utile sensatorum prouidencia diurne tradere memorie ${ }^{105}$ queque utilia dicta uel facta literarum ${ }^{106}$ apicibus assignata. Iccirco ${ }^{107}$ nos episcopi Martinus scilicet Ouetensis et lohannes Lucensis, inter Ouetensem ecclesiam et Lucencem diu habitam controuersiam nunc pio studio et amore fraterno utilitate utrobique prouisa sequestra pace compositam studuimus stilo tradere fideli sub cyrografi ${ }^{108}$ iusticia literis ${ }^{109}$ adnotatam. Conuenientes itaque nos duo pontifices cum maioribus utiusque $^{110}$ ecclesie apud Salamanticam ${ }^{111}$, gloriosissimi imperatoris domini Adefonsi in presentia ${ }^{112}$ cui ad hoc tractandum erat amor sumus ${ }^{113}$ et deuocio necnon a Romana curia hoc agendum data simul et iniunta ${ }^{114}$ permissio, presente lohanne primate Toletano, P. ${ }^{115}$ electo lacobensi necnon episcopus U. ${ }^{116}$ Secobiensi, E. ${ }^{117}$ Auilensi, R. ${ }^{118}$ Palentino, P. ${ }^{119}$ Segontino, I. ${ }^{120}$ Oxomensi ${ }^{121}$, U. ${ }^{122}$ Burgensi,

\footnotetext{
103 B] recurrsus.

104 B] uetustate.

105 B] memoriae.

106 B] litterarum.

107 B] Idcirco.

108 B] cirographi.

109 B] litteris.

110 B] utriusque.

111 B] Salamanticam urbem.

112 B] presencia.

113 B] summus.

114 B] iniuncta.

115 B] Pelagio.

116 B] Uincencio.

117 B] Enego.

118 B] Raimundus.

119 B] Petro.

120 B] lohanne.

121 B] Exomensi.

122 B] Uictore.
}

Nauarrone Salamanticensi, S. ${ }^{123}$ Zamorensi, P. ${ }^{124}$ Astoricensi, P. Dumiensi ${ }^{125}, \mathrm{M}^{126}$ Auriensi, necnon abbatibus, clericis et ecclesiastici ordinis religiosis innumeris personis adstantibus, presente etiam fere tocius ${ }^{127}$ regni obtimatum frequentia ${ }^{128}$, negocium nostrum deuotis mentibus affectibus, piis nulla interueniente ${ }^{129}$ perturbacione ${ }^{130}$, in magna pace, in summo gaudio effectui, mancipauimus pio modo et ordine infrascripto. Dedit siquidem imperator piissimus ${ }^{131}$ Ouetensi ecclesie regalia sua quecumque habebat inter duo flumina Nauiam et Ouem, castellum scilicet Suaron cum omnibus regalibus et cum integra sua mandatione, etiamque inter alia duo flumina Nauram et Nilonem aliam mandationem que uulgo Regarias nucupatur ${ }^{132}$, tali siquidem intencione et pactione ${ }^{133}$, ut his premissis usque in finem seculi Ouetensis ecclesia iure hereditario perfruatur. Et Lucensis ecclesia, diocesim ${ }^{134}$ Gallecie, de qua inter utrasque sedes dudum erat contencio ${ }^{135}$, per terminos statutos scilicet Neyram superiorem et inferiorem, Uallongam, Flamosum, Sarriam, Froianus ${ }^{136}$, Lemus, Uerosmo, Sauinianus ${ }^{137}$, Paramuso ${ }^{138}$, Asma, Camba, Dezon et Auuancos ${ }^{139}$, usque in mundi terminum inrefragabiliter ${ }^{140}$ pociatur. Nunc quoque post tale decretum imperatoris et curie sue, post tantam eius exibitam benignitatem, post tatam ${ }^{141}$ ecclesiarum ambarum compositam et paratam utilitatem et pacem, ego Martinus, Ouetensis episcopus, in comuni ${ }^{142}$ capitulo Ouetensis eccle$\mathrm{sie}^{143}$ cum archidiaconibus et canonicis omnibus et cum filiis ecclesie nobilibus laicis ${ }^{144}$ quibus facultas dedit adesse, renunciaui, firmaui et adscripsi predictam diocesim per supra scriptos terminos Lucensi ecclesie repositis in manu et in ${ }^{145}$ potestate lohannis Lucensis episcopi et archidiaconorum suorum Pelagii uidelicet ${ }^{146}$ et Roderici, firmamentis atque auctoritatibus regalium testamentorum et priuilegiorum Romanorum que erant de ipsa diocesi in Ouetensi ecclesia, facto scripto, firmato uerbo, adstricto pacto, ueritate asstructa ${ }^{147}$, quod Ouetensis ecclesia usque in finem seculi in inquietacionem ${ }^{148}$ neque repeticionem ${ }^{149}$ predicte diocesis contra Lucensem ecclesiam ull[aten]us [in]surgat,

\footnotetext{
123 B] Stephano.

124 B] Petro.

125 B] Pelagio Mindoniensi.

126 B] Martino.

127 B] totius.

128 B] frequencia.

129 B] int<er>ueniente.

130 B] perturbatione.

131 B] piissimus imperator.

132 B] nuncupatur.

133 B] pauctione.

134 B] diocesin.

135 B] contempcio.

136 B] Froianos.

137 B] Sauinianos.

138 B] Peramos.

139 B] Auiancos.

140 B] irrefragabiliter.

141 B] tantam.

142 B] communi.

143 B] ecclesiae.

144 B] laycis.

145 B] im.

$146 \mathrm{~B}]$ videlicet

147 B] astructa.

148 B] inquietationem.

149 B] repetitionem.
} 
non uerbo, non suggestione, non querimonia, non testamentis, non priuilegiis nec aliqua inquietatione uel surepcione $^{150}$, ecclesiaque Lucensis utatur ipsa diocesi usque in finem seculi secure, remota omni infestacione. Si[militer] ex parte [alia] post tale decretum imperatoris et curie sue post tantam eius exibitam ${ }^{151}$ benignitatem, post tantam ecclesiarum ambarum compositam et paratam utilitatem et pacem, ego lohannes, Lucensis episcopus, in comuni ${ }^{152}$ capitulo Lucensis ecclesie, cum archidiaconibus et canonicis omnibus et cum filiis ecclesie nobilibus laicis ${ }^{153}$ quibus facultas dedit adesse, renunciui ${ }^{154}$, firmaui et adscripsi per Penna Clamatoria, per Monterio ${ }^{155}$, ad Pandum de Zain ${ }^{156}$, ad tedas $^{157}$ de Monte Alto, ad Arcas $^{158}$ de Ma>gistru ${ }^{159}$ usque ad III ${ }^{160}$ fontes et contra hoc termino $<[. . . . . .]^{161}$ Ouetensi ecclesie repositis in manu et potestate Martini Ouetensis episcopi et archidiaconorum suorum lohannis et Petri, firmamentis atque auctoritatibus ${ }^{162}$ regalium testamentorum et priuilegiorum romanorum que erant de ipsis ecclesiis in Lucensi ecclesia, facto scripto, firmato uerbo, adstracto pacto, ueritate asstructa ${ }^{163}$, quod Lucensis ecclesia usque in finem seculi in inquietacionem ${ }^{164}$ neque in repeticionem ${ }^{165}$ predicte diocesis contra Ouetensem ecclesiam ullatenus insurgat, non uerbo, non suggestione, non querimonia, non testamentis, non priuilegiis nec aliqua inquietatione uel surepcione ${ }^{166}$, ecclesiaque Ouetensis utatur ipsa diocesi usque in finem seculi secure, remota omni infestatione. Si quis igitur presentium ${ }^{167}$ uel futurorum, tam nos presentes episcopi quam aliquis successorum nostrorum uel extraneorum archiepiscopus, episcopus, archidiaconus, clericus, rex, co[mes], uicecomes, secularis uel ecclesiastica persona, diaboli consilio armatus et antique malicie ueneno $c>r<a p u l a t u s$, hanc factam pacem, hanc firmatam pacem, hanc firmatam diffinicionem ${ }^{168}$ inter utrasque sedes frangere uel inquietare presumserit ${ }^{169}$, sit maledictus et excomunicatus usque in septimam generationem et cum Datam et Abirone ${ }^{170}$, cum Simone Mago et Nerone et cum luda, Domini prodictore ${ }^{171}$, et cum diabolo et angelis eius luat penas in eterna dampnatione, et ex parte qua emerserit ${ }^{172}$ iniuria controuersionis persoluat alie parti quod impugnauerit in dupplo ${ }^{173}$ in super mille marcas argenti, et ad partem regis aliud tantum.

\footnotetext{
150 B] subrrectione.

151 B] exhibitam.

152 B] communi.

153 B] laycis.

154 B] renunciaui.

155 B] Montemrio.

156 B] Ihain.

157 B] tendas.

158 B] Archas.

159 B] magistro.

160 B] tres.

161 E] ecclesiarum de Aspela.

162 B] actoritatibus.

163 B] adstricto pacto, ueritate astructa.

164 B] inquietationem.

165 B] repetitionem.

166 B] subreptione.

167 B] presencium.

168 B] diffinitionem.

169 B] presumpserit.

170 B] Abiron.

171 B] proditore.

172 B] emersit.

173 B] duplo.
}

Facta serie conuencionis ${ }^{174}$ seu diffinicionis ${ }^{175}$ IIII으 X응

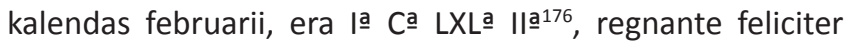
imperatore domno Adefonso qui et hanc Dei instictu ${ }^{177}$ effecit diffinicionem ${ }^{178}$ cum coniuge sua imperatrice Rricha et filiis suis regibus Sancio et Fernando in Legione, Toleto, Baecia et Almaria. Nos supradicti presules Martinus scilicet Ouetensis et lohannes Lucensis hanc seriem diffinicionis ${ }^{179}$ quam fieri iussimus et legere audiuimus in utriusque ecclesie capitulo manibus nostris roborauimus ${ }^{180}$ et signa iniecimus (S S).

(1 $\underline{a}$ col.) Ciprianus, abbas et canonice prior, conf.lohannes Falco, archidiaconus ${ }^{181}$, conf.- Gundisaluus, archidiaconus $^{182}$, conf.- Stefanus, archidiaconus ${ }^{183}$, conf.- Petrus, archidiaconus $^{184}$, conf.- Petrus Pardus, archidiaconus ${ }^{185}$, conf.- Didacus archidiaconus ${ }^{186}$ conf.

$\left(2^{a} \text { col. }\right)^{187}$ lohannes, primiclerus, conf.- Martinus, capelanus ${ }^{188}$, conf.- lohannes Roseus conf.- Et omnes canonici ouetenses conf. ${ }^{189}$

(3므 col.) Iterius, magister ${ }^{190}$, conf.- Iohannes Diaz, archidiaconus, conf. ${ }^{191}$

Petrus testis. Iohannes testis. Martinus testis. ${ }^{192}$

(4 $\underline{\underline{a}}$ col.) Petrus Gulmar[... $]^{193}$, canonice prior, conf.Rodericus, archidiaconus ${ }^{194}$, conf.- Pelagius archidiaconus ${ }^{195}$ conf.- Petrus, iudex et archidiaconus ${ }^{196}$, conf.- Magister Suarius et archidiaconus conf.- Didacus, primiclerus ${ }^{197}$, conf.Micaehl tesaurarius ${ }^{198}$ conf.

(5 $\underline{a}$ col. $)^{199}$ Petrus Micaelici, notarius episcopi ${ }^{200}$, conf.Fernandus, capellanus ${ }^{201}$, conf.- Iohannes Micaehlici ${ }^{202}$ conf.Et omnes Lucenses canonici ${ }^{203}$ conf. ${ }^{204}$

174 B] conuentionis.

175 B] diffinitionis.

176 B] LXXXXII‥

177 B] instinctu.

178 B] diffinitionem.

179 B] diffinitionis.

180 B] roboramus.

181 B] Archidiaconus lohannes Falco.

182 B] Archidiaconus Gundissaluus.

183 B] Archidiaconus Stephanus.

184 B] Archidiaconus Petrus.

185 B] Archidiaconus lohannes conf.- Archidiaconus Petrus Pardus.

186 B] Archidiaconus Didacus.

187 B une en una sola las columnas 1 y 2 de A.

188 B] capellanus.

189 B añade: Abbas domnus Petrus Sancti Uincencii cum omni suo conuentu conf.

190 En B aparece en la primera columna.

191 En B aparece sin patronímico, en la primera columna, en el grupo de los arcedianos.

192 B] Gundissaluus testis. Didacus testis. Pelagius testis.

193 B] Golmariz.

194 B] Archidiaconus Rudericus.

195 B] Archidiaconus Pelagius.

196 B] ludex Petrus et archidiaconus.

197 B] Archidiaconus Petrus conf.- Didacus primiclerus.

198 B] Michael thesaurarius.

199 En una única columna.

200 B] Petrus, cancellarius episcopi.

201 B] Capellanus Fernandus.

202 B] lohannes Menendiz capellanus.

203 B] canonici Lucenses.

204 B] Guterrus Sancii qui notuit. 
1156, agosto, 17. Narni.

Adriano IV concede la protección apostólica al obispo Juan y a la Iglesia catedral de Lugo, confirmándole en la posesión de las parroquias de Navia de Suarna, Valonga, Chamoso, Neira, Sarria, Froián, Páramo, Saviñao, Lemos, Verosmo, Asma, Abeancos Camba y Deza, que ya habían concedido sus antecesores, así como las heredades donadas por el conde Raimundo y la reina Urraca.

\author{
A.- Pergamino. Sello pendiente de plomo, anv.: ADRIANVS \\ PAPA IIII; rev.: SANCTUS PAULUS, SANCTUS PETRUS. En \\ muy mal estado de conservación, con grandes pérdidas \\ de texto. \\ Archivo de la Catedral de Lugo, Pontificios, legajo 3, № 6 . \\ B.- Copia simple en cartulario del siglo XIII. Omite las \\ suscripciones \\ Archivo Histórico Nacional, Códices y cartularios, \\ 1043B, 40r-v. \\ Ed.: López Sangil y Vidán Torreira, «Tumbo Viejo de \\ Lugo», no 88, pp. 182-183 (de B).
}

ADRIANUS EPISCOPUS, SERUUS SERUORUM DEI, UENERABILI FRATRI IOHANNI, LUCENSI EPISCOPO, EIUSQUE SUCCESSORIBUS CANONICE SUBTITUENDIS IN PERP[ETUUM. In eminenti apostolice se]dis specula, disponente Domino, constituti, ex iniuncto nobis a Deo apostolatus officio, fratres nostros episcopos diligere et ecclesiis sibi [a Deo commissis suam debeamus ius]titiam conseruare. Proinde uenerabilis in Christo frater lohanne episcope, tuis rationabilibus postulationibus clementer annuimus et [sanctam Lucensem beate Marie Virginis, glorio]se Dei genitricis ecclesiam cui Deo auctore preesse dinosceris sedis apostolice patrocinio communimus. Per presentis itaque priuilegii [paginam uniuersas ecclesias et loca que] infra antiquos parrochie tue terminos continentur, quemadmodum predecessores nostri felicis memorie URBANUS, PASCHALIS et INNOC[ENTIUS, Romani pontífices Lucensem de] illis pre[ceper]unt ecclesiam inuestiri et sicut pie recordationis PAPA CALIXTUS priuilegii sui munimine rationabiliter roborau[it et sicut etiam in eidem ecclesie antentici]s scriptis habetur, auctoritate apostolica tibi tuisque successoribus confirmamus. In quibus hec [propriis nominibus diximus annota]nda, Nauiam uidelicet, Valongam, Flamosam, Neiram, Sarriam, Froilanos, Parmam, Sau[nnos, Lemos, Verosma, Asmam Auiancos], Cambam, Deza. Quascumque preterea possessiones et quecumque bona in presentiarum eadem ecclesi[a iuste et canonice possidet, quicquid et] dono regum uel principum ei collatum esse cognoscitur seu aliis iustis modis [deinceps offerri contigent firma predicte] Lucense ecclesie et illibata permaneant. Confirmamus quoque hereditates quas [egregie memorie Raimundus consul una cum] uxore sua regina Vracca ecclesie Lucense concessit, Varzenam scilicet atque Caule[um et quecumque post iuri sui obitum] prefata regina eidem loco noscitur contulisse. Decernimus ergo ut nulli omnino hominum [liceat supradictam ecclesiam temere, per]turbare, aut eius possessiones auferre uel ablatas retinere, minuere, [set quibuslibet uexationibus fatigare, set] illibata omnia et integra conseruentur, eorum pro quorum guber[natione et sustentatione concessa sunt usi] bus omnimodis profutura, salua nimirum apostolice sedis [auctoritate et Bracharensis metropolitanis] iure ac debita reuerentia. Si qua igitur in futurum ecclesias[tica secularisue persona hanc nostre cons]titutionis paginam sciens contra eam temere uenire temptauerit, [secundo tertioue conmunita, non presumptionem suam congr]ua satisfactione correxerit, potestatis [honorisque sui dignitatem careat, reamque se diuino iudicio exis]tere, [de] perpetrata iniquitate cognos[cat, et a sacratissimo corpore ac sanguine Dei et domni redemptoris nos]tri Ihesu Christi aliena fiat [atque in extremo examine districte ultioni subiaceat. Cunctis aute]m eidem loco sua iura [seruantibus sit pax Domini nostri Ihesu Christi quatinus et hic fructum bono actionis] percipiant et apud dis[trictum iudicem premia eterne pacis inueniat. Amen, amen, amen].

[(S) Ego Adrianus], Catholicae aecclesiae episcopus, subscripsi. Bene Valete.

(1a col.) [+ Ego Ymarus,] Tusculanus episcopus, subscripsi.- [+ Ego Cencius, Portuensis] et sancte Rufine episcopus, subscripsi.- [+ Ego Gregorius,] Sabinensis episcopus, subscripsi.

(2 $\stackrel{a}{ }$ col. $)+$ Ego Guido, diaconus cardinalis sancte Marie [in Porticu, subscripsi].- + Ego lacintus, diaconus cardinalis sancte Marie in Co[smedin, subscripsi].

[Datum Narni per manum Rolandi, sancte Romane ecclesie presbiteri et] cancellarii, XVI kalendas septembris, indictione $\mathrm{IIII}^{\text {ta }}$, Incarnationis dominice anno M으 C으 L으 VI으, pontificatus uero domni ADRIANI PAPAE IIII anno secundo.

9

1157, agosto, 2. Segni.

Adriano IV confirma la concordia establecida entre las diócesis de Lugo y Oviedo con la mediación de Alfonso VII, por la cual Lugo obtenía la jurisdicción eclesiástica sobre los territorios de Neira, Valonga, Chamoso, Sarria, Froián, Lemos, Verosmo, Saviñao, Páramo, Asma, Camba, Deza y Abeancos.
A, Pergamino. Con daños que afectan al texto.
Archivo de la Catedral de Lugo, Pontificios, legajo 3, no 7.
B.- Copia simple en cartulario del siglo XIII. Omite las suscripciones.
Madrid, Archivo Histórico Nacional, Códices y cartula- rios, 1043B, 40v-41r.
Ed.: López Sangil y Vidán Torreira, «Tumbo Viejo de Lugo", no 89, pp. 183-185 (de B).

ADRIANUS episcopus, seruus seruorum Dei, venerabili fratri Iohanni, Lucensi episcopo, salutem et apostolicam benedictionem. Quotiens orte inter uiros ecclesiasticos controuersie concorditer ac pacifice aliquibus mediantibus terminantur, ad maiorem firmitatem habendam, apostolice sedis presidio eas necesse est communiri et nostre auctoritatis munimine roborari, ne forte ea que sunt pacifice instituta, processu temporis a memoria decidant posterorum et inrecidiue contentionis scrupulum debeant que iam scripta sunt deuenire. Eapropter uenerabilis in Christo frater episcope, tuis iustis postulationibus grato concurrentes assensu, concordiam quae super controuersia inter te et uenerabilem fratrem nostrum Martinum, quondam Ouetensem episcopum, diutius agitata, karissimo in Christo filio nostro Adefonso illustri Hyspaniarum rege partes suas interponente et studium adhibente utriusque partis assensu rationabiliter facta est, auctoritate sedis apostolice confirmandam 
et presenti scripto duximus muniendam. Que uidelicet concordia qualiter facta sit, sicut in instrumentis eiusdem filii nostri Adefonsi, Hyspaniarum regis et in alio scripto ab utroque uestrum exinde facto contineri dinoscitur, inferius inuenitur annexum. Prefatus siquidem rex regalia sua quecumque habebat inter duo flumina Nauiam et Ouem, castellum scilicet Suaron cum omnibus regalibus et cum integra sua mandatione et etiam inter alia duo flumina Nauram et Vilonem ${ }^{205}$ aliam mandationem que uulgo Regarias nuncupatur, pro bono ipsius pacis atque concordie, consilio uenerabilium fratrum nostrorum lohannis Toletani archiepiscopi et aliorum regni sui episcoporum et nobilium uirorum, principum atque comitum, suorum Ouetensi ecclesie pro anime sue salute donauit, tali siquidem intentione et pactione ut his quae premissa sunt eadem Ouetensis ecclesia hereditario iure in perpetuum [perfruatur, et Lucensis ecclesia diocesi] Gallecie, de qua inter utramque ecclesiam contentio fuerat diutius agitata, per statutos terminos scilicet Neiram Superiorem et Inferiorem, Vallongam, [Flamosum, Sarriam, Froianos, Le]mos, Verosmo, Sauinianos, Paramos, Asma, Camba, Dezon et Auiancos in perpetuum similiter irrefragabiliter potiatur. Post hanc [igitur predicti filii nostri regis utrique] ecclesie concessionem memoratus frater noster Martinus, tunc Ouetensis episcopus in communi capitulo Ouetensis ecclesie cum archidiaconis et omnibus canonicis [et quibusdam nobilibus laicis renunciauit], firmauit et asscripsit iamdictam dyocesim per suprascriptos terminos Lucensi ecclesie datis atque repositis in manu et potestate tua [atque archidiaconorum tuorum Pelagii uidelicet et Roderici, firmamentis et auctenticis] regalium instrumentorum et apostolice sedis priuilegiorum quae de ipsa dyocesi in Ouetense ecclesia erant. Facto [utique scripto, uerbo firmato et pacto astricto, quod Ouetensis ecclesia in repeccio]nem seu inquitationem predicte dyocesis aduersus Lucensem ecclesiam nullo tempore [insurgere debeat, sed Lucensis ecclesia ipsa diocesi omni infestacione remota perpetuo secure utatur. Tu quoque] in communi capitulo Lucensis ecclesiae cum archidiaconis atque omnibus ecclesie tue [canonicis et quibusdam nobilibus laicis renunciasti, firmasti et asscripsisti Ouetensi ecclesiae partem predi]cte dyocesis, per hos scilicet terminos, Pennam Clamatoriam, Montem Ruuim, [Pandum de lahin, Tendas de Monte Alto et Archas de Magistro usque ad Tres Fontes], datis atque repositis in manu et potestate supramemorati Martini, olim Ouetensis episcopi, et lohannis ac Petri archidiac[onorum suorum, firmamentis et auctoritatibus regalium instrumentorum et apostolice sedis] priuilegiorum quae de ipsis ecclesiis in Lucense ecclesia erant, facto similiter scripto, uerbo firmato et pacto astricto quod [Lucensis ecclesia in repetitionem seu inquietationem predicte diocesis contra] Ouetensem ecclesiam nullo tempore insurgat, sed eadem Ouetensis ecclesia ipsa dyocesi sine infestatione in perpetuum secure fruatur. [Vt autem predicta pax] atque concordia inter uos perpetuis temporibus inuiolabiliter obseruetur, eam auctoritate apostolica confirmamus, et presentis scripti patrocinio communimus. Statuentes ut nulli omnino hominum liceat hanc paginam nostre confirmationis infringere uel ei aliquatenus contraire. Si quis autem hoc attemptare presumpserit, secundo tertioue commonitus, nisi presump-

\footnotetext{
205 Sic pro Nilonem
}

tionem suam congrua satisfactione correxerit, potestatis honorisque sue dignitate careat, reumque se diuino iudicio existere de perpetrata iniquitate cognoscat, et a sacratissimo corpore ac sanguine Dei et Domini redemptoris nostri Ihesu Christi alienus fiat atque in extremo examine districte ultioni subiaceat. Seruantibus uero sit pax Domini nostri Ihesu Christi quatinus et hic fructum bone actionis percipiant et apud districtum iudicem premia eterne pacis inueniant, AMEN, AMEN, AMEN.

$(S)^{206}$ Ego Adrianus, Catholicae Aecclesiae episcopus, subscripsi. Bene Valete.

(1a col.) + Ego Hubaldus, presbiter cardinalis tituli sancte Praxedis subscripsi.- + Ego Hubaldus, presbiter cardinalis tituli sancte Crucis in lehrusalem subscripsi.- + Ego Iohannes, presbiter cardinalis sanctorum Iohannis et Pauli tituli Pamachii subscripsi.

(2- col.) + Ego lacintus, diaconus cardinalis sancte Marie in Cosmydyn subscripsi.- + Ego Bonadies, diaconus cardinalis sancti Angeli subscripsi.- + Ego Ardicio sancti Theodori diaconus cardinalis subscripsi.- + Ego Boso diaconus cardinalis sanctorum Cosme et Damiani subscripsi.

Datum Signiae per manum Rolandi, Sancte Romane ecclesie presbiteri cardinalis et cancellarii, IIII nonas augusti, indictione $\mathrm{V}$, incarnationis dominice anno M으 C으 느 VII으, pontificatus uero domni ADRIANI PAPAE IIII anno tertio.

\section{BiBLIOGRAFÍA}

Ayala Martínez, C. de 2017. «Poder real y episcopado en los reinos de León y Castilla (siglos XI-XII)», en L. C. Amaral (ed.): Um poder entre poderes. Nos 900 anos da restauração da Diocese do Porto e da construção do Cabido Portucalense: 249-274. Porto: Universidade Católica Portuguesa.

Barrau-Dihigo, L. 1919. "Étude sur les actes des rois asturiens (718910)». Revue Hispanique 46: 1-191.

Bresslau, H. 1998. Manuale di diplomática per la Germania e I'Italia. Roma: Ministerio per i beni culturali e ambientali.

Calleja-Puerta, M. 2018. «El valor de la escritura en los preámbulos de la cancillería de Alfonso VII», en C. M. Reglero de la Fuente (coord.), Poderes, espacios y escrituras. Los reinos de Castilla y León (siglos XI-XV): 179-202. Madrid: Sílex.

Camino Martínez, C. 2010. «Aprendizaje y modelos gráficos: entre el ámbito profesional y el privado», en P. M. Robinson (ed.), Teaching writing, learning to write. Proceedings of the XVIth Colloquium of the Comité International de Paléographie Latine: 205-222. London: King's College.

Cañizares, B. 1944. "Los grandes pleitos de la Iglesia de Lugo. La iglesia de Lugo y la de Oviedo». Boletín de la Comisión provincial de Monumentos Históricos y Artísticos de Lugo I (9): 229-232.

Cañizares del Rey, V. 2014. Colección diplomática II (857-1380). Lugo: Publicaciones Diócesis de Lugo.

Cheney, C. R. 1950. English Bishops' Chanceries, 1100-1250. Manchester: Manchester University Press.

Cunha, M. C. A. 2005. A Chancelaria Arquiepiscopal de Braga (10711244). Noia (A Coruña): Editorial Toxosoutos.

Cunha, M. C. 2017. «Os limites da diocese do Porto com as suas vizinhas de Braga e Coimbra: problemas e soluções», en L. C. Amaral (ed.): Um poder entre poderes. Nos 900 anos da restauração da Diocese do Porto e da construção do Cabido Portucalense; 147159. Porto: Universidade Católica Portuguesa.

D'Emilio, J. 2003. "Writing is the precious treasury of memory: scribes and notaries in Lugo (1150-1240)», en H. Spilling (ed.),

206 En la rueda: Oculi mei semper ad Dominum. En los cuarteles: SANCTUS PETRUS. SANCTUS PAULUS. ADRIANUS PAPA IIII. 
La collaboration dans la production de l'écrit médiéval. Actes du XIIle colloque du Comité international de paléographie latine (Weingarten, 22-25 septembre 2000): 379-410. Paris: École des Chartes.

D'Emilio, J. 2008. "The cathedral chapter of Lugo in the twelfth and thirteenth centuries: reform and retrenchment», en S. Barton y P. Linehan (eds.), Cross, Crescent and Conversion: Studies on Medieval Spain and Christendom in Memory of Richard Fletcher: 193-226. Leiden-Boston: Brill.

Domínguez Sánchez, S. 2003. Documentos pontificios referentes a la diócesis de León (siglos XI-XIII). León: Universidad de León.

Domínguez Sánchez, S. 2013. «El papel de los legados y de los jueces pontificios en la lucha de los obispados de León y Lugo por Triacastela», en K. Herbers, F. Engel y F. López Alsina (eds.), Das begrenzte Papsttum. Spielräume päpstlichen Handelns; Legaten, delegierte Richter, Grenzen: 237-250. Berlin: De Gruyter.

Eitel, A. 1914. "Rota und Rueda». Archiv für Urkundenforschung 5: 299-336.

Falque Rey, E. 1988. Historia Compostellana. Turnhout: Brepols.

Fernández de Viana y Vieites, J. I. 2003-2004. «Más notas sobre el Tumbo Viejo de Lugo». Acta historica et archaeologica mediaevalia 25: 593-604.

Fita, F. 1894. "Concilios nacionales de Salamanca en 1154 y de Valladolid en 1155». Boletín de la Real Academia de la Historia 24: 449-475.

Fletcher, R. A. 1977. «Regalian Right in Twelfth-Century Spain: the Case of Archbishop Martín of Santiago de Compostela». Journal of Ecclesiastical History 28 (4): 337-360. https://doi.org/10.1017/s0022046900041646

Fletcher, R. A. 1978. The Episcopate in the Kingdom of León in the Twelfth Century. Oxford: Oxford University Press.

Fletcher, R. 1994. "Las Iglesias del reino de León y sus relaciones con Roma en la Alta Edad Media hasta el Concilio IV de Letrán de 1215», en El reino de León en la Alta Edad Media, VI: 459-495. León: Centro de estudios e investigación "San Isidoro".

Flórez, H. 1793. España Sagrada, tomo XXXVIII. Memorias de la Santa Iglesia exenta de Oviedo concernientes a los siglos X, XI, XII, XIII y XIV fundadas en monumentos auténticos de su archivo, y de otros. Madrid: Oficina de Don Blas Román.

Floriano Cumbreño, A. C. 1946. Diplomática española del período astur. Estudio de las fuentes documentales del reino de Asturias (718-910). Oviedo: Instituto de Estudios Asturianos.

Frenz, Th. 1998. I documenti pontifici nel Medioevo e nell'Età Moderna. Città del Vaticano: Scuola Vaticana di Paleografia, Diplomatica e Archivistica.

García Larragueta, S. A. 1962. Colección de documentos de la Catedral de Oviedo. Oviedo: Real Instituto de Estudios Asturianos.

García Muñoz, P. 2016. La organización y descripción de un archivo catedralicio en el siglo XVIII. Estudio y edición del Libro Maestro, ms. 53 del Archivo Capitular de la Catedral de Oviedo. tesis doctoral inédita. Oviedo: Universidad de Oviedo.

Guyotjeannin, O. 1993. "L'influence pontificale sur les actes épiscopaux français (Provinces écclesiastiques de Reims, Sens et Rouen, Xle-XIle siècles)», en R. Grosse (ed.), L'Église de France et la papauté (Xe-XIIle siècle): 83-102. Bonn: Bouvier Verlag.

Guyotjeannin, O. y Morelle, L. 2007. «Tradition et réception de l'acte médiéval. Jalons pour un bilan des recherches». Archiv für Diplomatik 53: 367-404. https://doi.org/10.7788/afd.2007.53.jg.367

Henriet, P. 2008. "Territoires, espaces symboliques et "frontières naturelles". Remarques sur la carte diocésaine hispanique du XIle siècle», en F. Mazel (ed.), L'espace du diocèse. Genèse d'un territoire dans l'Occident médiéval (Ve-XIIle siècle): 287-307. Rennes: Presses Universitaires de Rennes.

Herde, P. y Jakobs, J. (eds.) 1999. Papsturkunde und europäisches Urkundenwesen. Studien zu ihrer formalen und rechtlichen Kohärenz vom 11. bis 15. Jahrhundert. Köln-Weimar-Wien: Böhlau Verlag.

Linehan, P. 2009. «Un quirógrafo impugnado. Zamora y la cultura jurídica zamorana a comienzos del siglo XIII». Anuario de Estudios Medievales 39 (1): 127-176. https://doi.org/10.3989/aem.2009.v39.i1.99
López Sangil, J. L. y Vidán Torreira, M. 2011. «El Tumbo Viejo de Lugo (trancripción completa)». Estudios Mindonienses 27: 11-373.

Lucas Álvarez, M. 1986. El Tumbo de San Julián de Samos (siglos VIIIXII). Santiago de Compostela: Caixa Galicia.

Lucas Álvarez, M. 1993. El reino de León en la Alta Edad Media, V. Las cancillerías reales (1109-1230). León: Centro de estudios e investigación "San Isidoro".

Mansilla Reoyo, D. 1994. Geografía eclesiástica de España. Estudio histórico-geográfico de las diócesis. Roma: Iglesia Nacional Española.

Marques, M. A. F. 1996. «A restauração das dioceses de Entre Douro e Tejo e o litígio Braga-Compostela», en 20 Congresso histórico de Guimarães. Actas do congreso, volumen 5. Sociedade, administração, cultura e igreja em Portugal no séc. XII: 49-84. Guimarães: Câmara Municipal.

Marques, J. 2016. Liber Fidei Sanctae Bracarensis Ecclesiae. Braga: Arquidiocese de Braga.

Martín López, E. 1994-1995. «La carta partida como forma de validación». Estudis catellonencs 6: 839-855.

Menéndez Pidal de Navascués, F. 1998. "Los sellos de Alfonso VII", en J. M. Soto Rábanos (ed.), Pensamiento medieval hispano. Homenaje a Horacio Santiago-Otero: I, 99-116. Madrid: CSIC.

Migne, J.-P. 1855. Patrologia Latina, tomus CLXXX. Paris: J.-P. Migne.

Miguel Vigil, C. 1887. Asturias monumental, epigráfica y diplomática. Datos para la historia de la provincia. Oviedo: Imprenta del Hospicio Provincial.

Miguélez Cavero, A. 2010. «El poder gestual de la mano en la sociedad medieval y su reflejo en la iconografía de los siglos del románico en la Península Ibérica». Medievalismo. Revista de la Sociedad Española de Estudios Medievales 20: 125-147.

Mosquera Agrelo, M. 2002a. "La diócesis de Lugo en la Edad Media», en J. García Oro (ed.), Historia de las diócesis españolas, 15. Iglesias de Lugo, Mondoñedo-Ferrol y Orense: 21-94. Madrid: Biblioteca de Autores Cristianos.

Mosquera Agrelo, M. 2002b. "Stant Gotice Scriptum in tomo Decimo Palatii. Os documentos do "Libro Décimo de Pergamiños" do Arquivo Catedralicio de Lugo», en M. Romaní Martínez y M. A. Novoa Gómez (eds.), Homenaje a José García Oro: 211229. Santiago de Compostela: Universidade de Santiago de Compostela.

Ostos Salcedo, P. 1995. "Documentos y cancillería episcopal de Burgos anterior a 1300», en Ch. Haidacher y W. Köfler (eds.), Die Diplomatik der Bischofsurkunde vor 1250 - La diplomatique épiscopale avant 1250: 429-451. Innsbruck: Tiroler Landsarchiv.

Pallares y Gayoso, J. 1700. Argos divina. Sancta María de Lugo de los Ojos Grandes.... Santiago: Imp. de Benito Antonio Frayz.

Pardo Rodríguez, M. L. 1999. "La rueda hispana: validación y simbología», en P. Herde y H. Jakobs (eds.), Papsturkunde und europäisches Urkundenwesen. Studien zu einer formalen und rechtlichen Kohärenz vom 11. bis 15. Jahrhundert: 241-258. KölnWeimar-Wien: Böhlau Verlag.

Pérez de Urbel, J. 1952. Sampiro, su crónica y la monarquía leonesa en el siglo X. Madrid: CSIC.

Poole, R. L. 1915. Lectures on the History of the Papal Chancery down to the time of Innocent III. Cambridge: University Press.

Pueyo Colomina, P. 2014. «Documentos episcopales y capitulares (ss. XII-XV)», en F. J. Molina de la Torre, I. Ruiz Albi y M. Herrero de la Fuente (eds.), Lugares de escritura. La catedral: 131-179. Valladolid: Universidad de Valladolid.

Rassow, P. 1928. "Die Urkunden Kaiser Alfons'VII. von Spanien. Eine palaeographisch-diplomatische Untersuchung». Archiv für Urkundenforschung X (3): 328-467.

Rassow, P. 1929. "Die Urkunden Kaiser Alfons'VII. von Spanien. Eine palaeographisch-diplomatische Untersuchung». Archiv für Urkundenforschung XI (1): 66-137.

Recuero Astray, M., González Vázquez, M. y Romero Portila, P. 1998. Documentos medievales del reino de Galicia: Alfonso VII (11161157). Santiago de Compostela: Xunta de Galicia.

Reglero de la Fuente, C. 2006. «Los obispos y sus sedes en los reinos hispánicos occidentales», en La reforma gregoriana y su proyección 
en la cristiandad Occidental, siglos XI-XII: 195-288. Pamplona: Gobierno de Navarra.

Reglero de la Fuente, C. 2014. «Reyes y obispos en los reinos de León y Castilla (c. 1050- c. 1200): oración, servicio y memoria», en M. D. Teijeira Pablos, M. V. Herráez Ortega y M. C. Cosmen (eds.), Reyes y prelados. La creación artística en los reinos de León y Castilla (1050-1500): 45-66. Madrid: Sílex.

Reilly, B. F. 1974. "The court bishops of Alfonso VII of León-Castilla, 1147-1157». Mediaeval Studies XXXVI: 67-78.

https://doi.org/10.1484/j.ms.2.306157

Reilly, B. F. 1978. "On getting to be a bishop in Leon-Castile: the "emperor" Alfonso VII and the post-Gregorian Church». Studies in medieval and renaissance history 11: 35-68.

Reilly, B. F. 1998. The Kingdom of León-Castilla under King Alfonso VII, 1126-1157. Philadelphia: University of Pennsylvania Press.

Risco, M. 1798. España Sagrada, tomo XLI, de la Santa Iglesia de Lugo. Continuación de su Historia desde el siglo XII hasta fines del XVIII. Documentos desconocidos e inéditos hasta ahora, y relativos a la ilustración de las memorias que se publican. Madrid: Viuda e hijo de Pedro Marín.

Rodríguez Díaz, E. E. 1992. "Elaboración, uso y función de los códices del scriptorium episcopal ovetense a fines del siglo XIV». Historia. Instituciones. Documentos 19: 403-412.
Rodríguez Díaz, E.E. 1995. El libro de la Regla Colorada de la Catedral de Oviedo. Estudio y edición. Oviedo: Real Instituto de Estudios Asturianos.

Sánchez Belda, L. 1953. Documentos reales de la Edad Media referentes a Galicia. Catálogo de los conservados en la sección Clero del Archivo Histórico Nacional. Madrid: Dirección General de Archivos y Bibliotecas.

Sanz Fuentes, M. J. 1995a. "Transcripción», en Liber Testamentorum Ecclesiae Ovetensis: 455-456. Barcelona: Moleiro.

Sanz Fuentes, M. J. 1995b. «Documento y cancillería episcopal en Oviedo anterior a $1300 »$, en Ch. Haidacher y W. Köfler (eds.), Die Diplomatik der Bischofsurkunde vor 1250 - La diplomatique épiscopale avant 1250: 467-482. Innsbruck: Tiroler Landsarchiv.

Sanz Fuentes, M. J. 2014. La reescritura del pasado: el "Liber Testamentorum" de la Catedral de Oviedo. Oviedo: Universidad de Oviedo.

Tock, B.-M. 1991. Une chancellerie épiscopale au XIle siècle: Le cas d'Arras. Louvain-la-Neuve: Université Catholique de Louvain.

Vázquez Saco, F. 1947. "Un diploma de Alfonso VII». Boletín de la Comisión provincial de monumentos históricos y artísticos de Lugo II: 285-298.

Weiss, S. 1995. Die Urkunden der päpstlichen Legaten von Leo IX. bis Coelestin III. (1049-1198). Köln-Weimar-Wien: Böhlau Verlag. 